Chapter 36

\title{
The Ontogeny of Taste Perception and Preference Throughout Childhood
}

\author{
Catherine A. Forestell and Julie A. Mennella
}

\subsection{INTRODUCTION}

The study of the ontogeny of human taste perception has been the focus of scientific investigations for more than a century (as summarized in Table 36.1). From this knowledge base, we now know that humans are born with a well-developed peripheral taste system-a taste system that, by the last trimester of pregnancy, is capable of conveying information to the central nervous system. This information is made available to brain structures critical for organizing a variety of consummatory (e.g., intake) and reflex-like (e.g., facial expressions) behaviors; (see Ganchrow and Mennella, 2003, for an earlier review). Clearly, taste plays an important role in determining whether a foreign substance should be accepted or rejected, and informs the gastrointestinal system about the quality and quantity of the impending rush of nutrients (Egan and Margolskee, 2008; Sclafani, 2007). Although the taste system involves innate responses, these responses change and mature throughout childhood, as will be described in this chapter (e.g., Cowart, 1981; Mennella et al., 2010b; Stein et al., 1994).

The sense of taste has taken on great interest in recent years because it is a major determinant of the food acceptance patterns of children (Birch 1998). Thus, our accumulating knowledge about taste plays an important role in understanding the basis for food choices in children. Although the modernization and industrialization of the food supply have produced many benefits, diets rich in sugars and salt and low in fruits and vegetables have become increasingly commonplace, thereby producing unanticipated consequences. For example, excessive intake of foods containing high amounts of salt or sugars (and, consequently, foods that taste salty and sweet) causes or exacerbates a number of illnesses, including hypertension, diabetes, and metabolic syndrome (Mokdad et al., 2004). Reduced intake of fruits and vegetables increases the risk of a number of chronic diseases, including cardiovascular diseases and certain cancers (Knai et al. 2006). Because eating vegetables as part of an overall healthy diet can aid in weight management for children and adults (Blanck et al., 2008; Lakkakula et al., 2008; McCrory et al., 1999), their reduced intake likely contributes to the obesity epidemic.

In this chapter, we focus on the approaches and discoveries that have contributed to our current knowledge of human development of the five "basic" tastes of sweet, sour, salty, bitter, and umami (savory) and the impact they have had on our understanding of the sensory world of children. This review is not meant to be representative of all research conducted to date; rather, it highlights the breadth of methodologies employed, the convergence of findings, and extant gaps in knowledge. Although a detailed treatment of taste anatomy is beyond the scope of this begin by providing an overview of the mechanisms underlying taste sensations and when they emerge during development.

\subsection{THE ONTOGENY OF TASTE PERCEPTION}

Taste, or gustation, refers to the sensation that occurs when chemicals stimulate taste receptors located on a 
large portion of the tongue's dorsum and other parts of the oropharynx, such as the larynx, pharynx, and epiglottis. Flavor, in contrast, is elicited by a combination of tastes and odors experienced orthonasally and retronasally while consuming substances. Taste is initiated at taste receptors, which are localized in taste buds and are innervated by branches of three cranial nerves: the facial (VIIth), glossopharyngeal (IXth), and vagal (Xth) nerves. The taste stimuli that interact with these receptors are often separated into a small number of "primary" taste qualities: sweet, salty, bitter, sour, and umami.

Contemporary knowledge about the development of the five basic taste qualities stems from research that has examined receptor morphogenesis and functional maturity (for review, see Bradley and Mistretta, 1975; Cowart et al., 2004; Ganchrow and Mennella, 2003). Early research conducted in this and when the taste system becomes funetional and its subsequent pattern of development throuthouth revealed that taste buds begin to emerge throughout the oral cavity, including the dorsal surface of the tongue, palatoglossal arches, palate, posterior surface of the epiglottis, and posterior wall of the oropharynx, just 8 weeks after conception By 13 weeks, taste buds begin to resemble those of the adult and are found throughout the oral cavity (Bradley and Mistretta, 1975; Bradley and Stern, 1967; Hersch and Ganchrow, 1980; Witt and Reutter, 1996; 1998). Taste pores, which provide access for tastants to interact with taste bud receptor cells, are generally considered as markers of functional maturity (Mistretta, 1972). Such pores have been identified in fetal fungiform papillae before the end of the fourth month (Witt and Reutter, 1996; 1998). At birth, the newborn infant is endowed with a rich population of gustatory receptors associated with such pores.

It is probably not a coincidence that the timing of these developmental changes corresponds to the emergence of fetal sucking and swallowing behavior. Ultrasound studies have revealed early development of swallowing and ora sensorimotor function at approximately 15 weeks gestational age (Miller et al., 2003; Ross and Nijland, 1997) By term, infants are actively swallowing between 500 and $1000 \mathrm{ml} /$ day of amniotic fluid (Pritchard, 1965; Ross and Nijland, 1997). This not only represents a major route of amniotic fluid absorption but also serves to stimulate the taste buds and influence their synaptic connections. The chemosensory composition of the amniotic fluid is constant flux throughout pregnancy, especially once the fetus begins to urinate, exposing the newly developed taste buds to varying concentrations of a variety of chemicals, including sugars, sodium and potassium salts, various acids (Liley, 1972), and flavors from the mother's diet (Mennella et al., 1995).

\subsection{RESEARCH APPROACHES AND METHODOLOGIES}

Table 36.1 presents an extensive summary of studies of taste sensitivity and preference during development, organized by taste quality, age group, and methodology. A variety of psychophysical methodologies have been employed to assess taste perception and preference throughout infancy, childhood, and adolescence. The method chosen depends on the objective of the study as well as the age (and, in turn, cognitive and language abilities) of the participants under study. These psychophysical studies on taste provide data relevant to two separate aspects of sensation: (1) the sensitivity of the system to chemical stimuli and (2) the hedonic valence, or pleasantness, of the sensation (Cowart, 1981; Cowart et al., 2004).

For preverbal children, the tools used often focus on reflex-like responses (e.g., salivation, sucking, heart rate, or orofacial responses) or consummatory responses. Interestingly, many of the experimental paradigms for this age group are similar to those used in animal studies (Berridge and Kringelbach, 2008; Boughter and Bachmanov, 2007; Glendinning et al., 2002; Grill and Norgren, 1978; Spector et al., 1981; Steiner et al., 2001). Because virtually all of these measures can be associated with acceptance or rejection, they presumably involve a hedonic component. As a result, sensitivity and hedonics are difficult to distinguish in animals and in nonverbal infants (Cowart et al., 2004).

For older children, a variety of methodological tools have been used, which vary according to their language and cognitive development. Measures of sensitivity include threshold detection $\overline{\mathbf{x}}_{\mathbf{2}}$ suprathreshold scaling procedures: hedonic measurements include ratings or ranking of stimuli. Several of these sensory methodological tools have been published in standard guides (ASTM International, 2003) and review articles (Popper and Kroll, 2005) and often are modifications of methods used in adult populations. However, the validity and reproducibility of many of these procedures have not been assessed for children.

Findings from this expanding collection of methodological tools are remarkably consistent across studies and laboratories throughout the world. In the sections that follow, we review the methodologies used with children of different ages and highlight findings that support the hypothesis that behaviors associated with gustatory function are robust during early development and contribute significantly to adaptation and survival of the developing infant and child. 


\subsection{TASTE SENSITIVITY IN THE FETUS}

A key question in the ontogeny of taste perception is whether function is present prior to birth. As summarized in Table 36.1, two approaches have been used to answer this important question: (1) indirect observations of the fetus and (2) direct observations of premature infants. Although the response of human fetuses to taste has never been directly investigated, indirect evidence from studies in fetuses together with findings from studies in premature infants, suggests that prenatal monitoring of some taste stimuli is possible during late gestation. Moreover, as alluded to earlier in the chapter, the fetus is exposed to a unique chemosensory environment prior to birth (for review, see (Mennella, 2007).

There are two reports of increased fetal swallowing following the injection of sweet stimuli such as saccharin into the amniotic fluid of pregnant women (DeSnoo, 1937; Liley, 1972), Decreased swallowing has been noted following analogous injection of bitter-tasting poppy seed oil (Liley, 1972). Such findings provide indirect evidence that the fetus is capable of tasting and differentially responding to bitter- and sweet-tasting substances.

Stronger evidence that the fetus can respond to taste stimuli comes from research on premature infants. To overcome methodological limitations caused by premature infants' immature suck-swallow coordination, innovative methods have been developed that avoid the risk of fluid aspiration. These include brief, intermittent presentations of small quantities of tastants (sometimes on absorbent cotton) directly into the oral cavity (Eckstein, 1927; Tatzer et al., 1985) and embedding tastants in a nipple-shaped gelatin media that release small amounts of tastants during mouthing or sucking (Maone et al., 1990). By measuring the strength, length, and latency of nonnutritive sucking to these tastants relative to a control, such as water, researchers have been able to infer sensitivity to, and preferences for, various tastants. This body of research revealed that newborns delivered preterm and tested postnatally produced stronger and more frequent sucking responses when offered a sucrose-sweetened nipple compared to an unsweetened gelatin-based nipple (Maone, Mattes et al., 1990), or to drops of sweetened solution compared to water (Tatzer, Schubert et al., 1985).

When small amounts of bitter or sour tastants were placed directly on the tongue of preterm infants, differential responding has been observed Eckstein (1927) found, for example that various concentrations of bitter-tasting quinine retarded sucking in most of the infants he studied, whereas a drop of pure lemon juice increased reflex salivation that was accompanied by increases in sucking vigor and, in some cases, retching. Taken together, this body of research suggests that by the last trimester, humans have a well-developed taste system capable of detecting and hedonically responding to sweet, bitter, and sour tastants.

\subsection{TASTE SENSITIVITY AND PREFERENCE DURING INFANCY}

\subsubsection{Sucking and Consummatory} Responses

Sucking and ingestive responses have been successfully used to study patterns of responses that occur as a function of individual and age-related differences in taste perception and preferences throughout infancy (summarized in Table 36.1). Methods include delivering small quantities of taste solutions (1-2 ml) applied directly to the tongue (Crook and Lipsitt, 1976; Crook, 1978), embedding tastants in a gelatin-based nipple (Maone et al., 1990), or providing brief (30-180 s) access to multiple bottles in succession which contain various taste or diluent solutions (Beauchamp et al., 1994; Beauchamp et al., 1986; Beauchamp and Moran, 1982; Beauchamp and Pearson, 1991; Kajuira et al., 1992). One can infer that the infant can detect the tastes, and to some extent that they prefer the taste solution (e.g., sweetened water) more than the diluent (e.g., water), if they consume more from the bottles that contain the taste solution than from those that contain the diluent solution (Beauchamp et al., 1986; Desor et al., 1973). Consistent with the findings for premature infants, research has repeatedly demonstrated strong acceptance of sweet-tasting sugars by the newborn. Within days after birth, they can not only detect dilute sweet solutions, but can also differentiate varying degrees of sweetness and different kinds of sugars (Desor et al., 1973). These findings converge with physiological findings that sweet tasting stimuli administered to newborn infants produced greater relative left-sided activation in both frontal and parietal regions of the brain, which is considered to be a reliable indicator of positive emotion (Fox and Davidson, 1986).

The early studies of Desor, Maller, and colleagues (Desor et al., 1975; Maller and Desor, 1973) found that newborns did not differentially consume bitter and sour solutions relative to water. Thus, it was not clear whether newborns failed to detect the taste solution or were indifferent to it. This conundrum was overcome by the adding sugar to the diluent making it slightly sweet $(0.07 \mathrm{M})$, raising its baseline ingestion above that of water, which is typically aversive to newborns. When citric acid was added to this weak sweet diluent, consumption of the solution was reduced, indicating that the citric acid could be detected 
and was aversive (Desor, Maller et al., 1975). However, they did not differentially consume a urea solution, which has a bitter taste. According to a later study, differential consumption of urea does not occur until infants are approximately 2 weeks of age, at which point they began to reduce their consumption of urea in a sweetened solution relative to the sweet diluent alone (Kajuira et al., 1992).

Another example of the importance of employing an appropriate diluent for taste testing in infants can be found in the research on umami taste. The early work of Steiner (1987) revealed that babies reject umami taste (e.g., amino acid L-glutamate, $5^{\prime}$-ribonucleotides) in water, presumably because the addition of glutamate decreases the palatability of water solutions. However, because glutamate tends to increase the palatability of food, more recent research with infants used the same method as for older children and adults, by providing the umami taste in a soup broth (Beauchamp and Pearson, 1991; Steiner, 1987; Vazquez et al., 1982) or an infant cereal base (Mennella et al., 2009) When the umami taste was presented in these food bases infants exhibited differential preference for umami by consuming more when glutamate was added to the diluent

A further methodological consideration for consummatory studies is that failure to control for basic stimuli (e.g., concentration, temperature, volume, and type of diluent) and methodological parameters (e.g., degree of satiation, experience, and age of the participants) may produce data that are variable and inconsistent. Many of these issues can be resolved by using a within-subject design. Mennella et al., (2009) fed, on different days, a familiar cereal that was adulterated with D-lactose (sweet), sodium chloride (salty), urea (bitter), citric acid (sour), or monosodium glutamate (umami). The presentation order of the cereal preparations was counterbalanced across days. During each test session, which occurred at approximately the same time of day and 30-60 minutes before the next scheduled feeding, mothers fed their infants while wearing a mask and refrained from talking, thereby eliminating potential influences of their facial or verbal responses on the infants' behaviors. Infants determined the pacing and duration of the feeding, and the experimenter, who was out of view of the mother-infant dyad, ended the feeding when the infant rejected the food on at least three consecutive occasions. Results indicated that infants' consumption of the different cereals was determined to some extent by their early feeding experiences: infants who had been fed protein hydrolysate formula (a formula that tastes bitter, savory and sour due to high levels of free amino acids) ate significantly more savory, bitter, sour, and plain cereals than did those who had been breastfed or formula-fed, and in formula-fed infants who were eating table foods, intake of the cereals with each of the basic tastes reflected the types of foods they had been fed. Thus, when grouping participants for data analyses, it is important to consider their early feeding history so that differences in taste preferences will not be masked by experience-related factors.

To what extent do early experiences alter or modulate the development of sweet preferences later in life? Early feeding patterns have been shown to modulate infants' innate preference for sweet tastes. Longitudinal studies have found that babies who were routinely fed sweetened water during the first months of life exhibited a greater preference for sweetened water during brief-access tests when tested at 6 months and then again at 2 years of age (Beauchamp and Moran, 1984; 1982) compared to those who had little or no experience with sweetened water. A more recent cross-sectional study of 6- to 10-year-old children supported these findings and revealed that such feeding practices may have longer term effects on the preference for sweetened water than previously realized (Pepino and Mennella, 2005b)

For salt, the story is more complex. Unlike innate responses to the other basic tastes, differential responses to salt are not exhibited by newborns. Rather, responsivity matures postnatally. While infants younger than 4 months of age consumed moderate concentrations of salt solution $(0.10-0.20 \mathrm{M})$ and water in equal amounts, those between 4 and 24 months of age consumed more of the salt solutions relative to water (Beauchamp et al., 1986; Desor et al., 1975b). Beauchamp and colleagues have argued that postnatal experience with salty tastes probably does not play a major role in this shift from apparent indifference to salt at birth to acceptance at 4 months of age, which instead may reflect postnatal maturation of central or peripheral mechanisms that underlie salt taste perception (Beauchamp and Cowart, 1985; Cowart and Beauchamp, 1990). Later research has demonstrated that infants younger than 4 months of age may not be completely indifferent to salt taste. When presented with moderate $(0.17 \mathrm{M})$ and strong $(0.34 \mathrm{M})$ concentrations of a salted solution relative to water at 2 months of age, they consumed significantly less of the strong salt solution relative to water, and their acceptance of both concentrations of salt was negatively associated with their birth weight (Stein, Cowart and Beauchamp, 2006).

Infants' acceptance of salty taste is also affected by prenatal experiences. Infants born to women who reported suffering from moderate to severe symptoms of morning sickness had significantly higher relative intake of salt solutions at 4 months of age than did those whose mothers reported having no more than mild morning sickness (Crystal and Bernstein, 1998). That these effects last beyond infancy is suggested by the finding that adolescents and young adults preferred higher concentrations of salt in a soup base in the laboratory, and reported significantly higher daily salt use, if either they had suffered from infantile vomiting or diarrhea themselves or their mothers had suffered from morning sickness while pregnant with them (Lesham, 1998). 
Like experience with sweet, experiences with salt provide the infant with opportunities to learn about the level of saltiness to be expected in foods. As has been observed with sweet taste, 6-month-old infants' consumption of moderate $(0.17 \mathrm{M})$ and strong $(0.34 \mathrm{M})$ salt solutions (Stein et al., 2012) or salted cereals (Harris, Thomas et al., 1990) can be modified by their dietary patterns once they start eating table foods. Relative to those who did not eat starchy foods, which are a significant source of sodium in infants' diets, those who ate these foods at home consumed significantly more of a solution or cereal when salt was added. Thus, it appears that although infants' hedonic responses to basic stimuli are innate, early experiences, some of which

\subsubsection{Orofacial Expressions}

Reflexive orofacial changes of both humans and animals to tastes and flavors have also been widely studied (see Table 36.1) (Berridge and Kringelbach, 2008; Forestell and Mennella, 2012; Grill and Norgren, 1978; Mennella et al., 2009; Spector et al., 1981; Spector and Travers, 2005). Similarities between species in their facial responses to taste stimuli (as reviewed in Berridge, 1996) suggest that such behavioral responsivity has evolved in a range of mammals and is clearly adaptive. It has been hypothesized that the small number of taste qualities evolved because of the functional importance of the perception of basic taste qualities in nutrient selection. Preference for salty, sweet, and savory tastes is thought to have evolved to attract us to that which is beneficial: salty-tasting minerals, energy-producing sugars, and vitamin- and protein-rich foods; in contrast, rejection of bitter-tasting substances may have evolved to protect mammals and other organisms from poisons, many of which are bitter (Glendinning, 1994; Jacobs, 1978).

Steiner (1973) was among the first to examine facial reactivity in detail to tastants in human infants. Evidence supporting the concept that these orofacial responses were innate and unlearned came from observations that they were present in both normal and anencephalic infants whose brainstems were intact within hours of birth and before their first postnatal feeding. In these pioneering studies, a drop of solution representing one of the basic taste qualities (i.e., sweet, sour, salty, bitter) was placed on the infant's tongue. Responses of normal and anencephalic infants were strikingly similar: when tasting sweet, their faces relaxed and they began suckling and smiling; in contrast, bitter tastes elicited gaping responses, while sour elicited squinting and lip pursing (Steiner, 1973, 1977, 1979). No facial response was evident to salt before the age of 4 months, which is consistent with findings from the consumption studies discussed above e.g., (Beauchamp et al., 1986). That normal as well as anencephalic infants demonstrated similar orofacial responses suggests that these responses are mediated in the region of the hindbrain and not in the cerebral cortex, where voluntary movement is controlled (Steiner, 1973, 1977).

Subsequently, Rosenstein and Oster (1988) employed a more precise method of describing orofacial responses with Ekman and Friesen's anatomically based Facial Action Coding System (FACS; Ekman and Friesen, 1978). By this system, virtually any facial expression can be dissected into its constituent action units (AUs). In Rosenstein and Oster's study, the percentages of infants who emitted particular reactions, or AUs, to sweet, sour, bitter, and salt solutions were measured. When initially tasting a sweet substance, infants transiently showed negative mid-face actions, such as cheek raising (AU 6) or nose wrinkling (AU 9). This was followed by more positive and sustained responses such as facial relaxation and sucking. In contrast to the observations of Steiner and colleagues (e.g., Ganchrow et al., 1983; Steiner, 1973), this study did not find marked smile-like facial responses to the presentation of sweet tasting stimuli (AU12). In response to sour and bitter tastants, infants reacted more negatively, as demonstrated mainly by their lower-face actions. For example, while both sour and bitter solutions elicited similar upper and midface AUs (which included cheek raises (AU 6)), sour solutions elicited lip pursing (AU 18), and bitter solutions elicited gaping (AU 26 and AU 27) Although no such FACS analysis has been conducted on the newborn's response to umami taste, Steiner (1987) has reported that the presentation of umami-tasting stimuli results in facial relaxation, sucking, and smiling in infants.

In more recent studies, slow-motion video analysi (Berridge, 1996) has been used to quantify the actual number of affective reactions infants express to a taste stimulus as a measure of the valence and intensity of an affective reaction (Mennella et al., 2009). A necessary requirement of this method is the need for trained individuals (preferably certified in FACS) to analyze the video images and establish reliability between their scores, which can be time-consuming and costly. In one study, the number of AUs each infant expressed in response to sweet, sour, bitter, savory, salty, and plain cereal over the first two minutes of each feeding session was recorded (Mennella et al., 2009). Because of marked individual differences in the display of faces, the analyses focused on the total number of facia expressions of distaste made for each spoonful offered, as well as the incidence of specific facial responses such as gapes and smiles. In general, infants made more facia responses related to distaste while eating the bitter cereal than while eating the other cereals. Moreover, those who had been fed protein hydrolysate formula or breast milk, both of which are higher in glutamate content than are formulas based on cow's milk, smiled more when fed the savory cereal than did those fed milk-based formulas. The effects of early exposure to flavors appear to be particularly 
persistent, lasting for several years. That is, children who were fed hydrolysate formulas as infants appear to be programmed to like not only the taste of protein hydrolysates but also the taste of foods that are more savory (e.g. chicken), sour (e.g., lemon), and bitter (e.g., broccoli) compared with children who were fed milk-based formulas (Liem and Mennella, 2002; Mennella and Beauchamp, 2002; Mennella et al., 2006; Schuett et al., 1985). These findings provide further evidence of the plasticity of the taste system such that the early diet can determine later preferences and dietary habits.

In summary, studies on orofacial responsivity to taste demonstrate that, like adults, infants can control the muscles required to express primary emotions and are thus well equipped to convey a wide range of emotional states and reactivity to tastes (Ekman and Oster, 1979). Moreover, the ability to discriminate all but one of the basic tastes (salt) is evident early in life, and infants can respond with characteristic facial responses that correspond to the hedonic valence of the taste stimulus. Thus, infants' facial expressions can provide caregivers with important information about whether they like or reject a food (Forestell and Mennella, 2007, 2012). Visually striking facial displays of gaping are readily identified by caregivers and thus provide preverbal infants with an efficient means to communicate their dislike of the taste of what they are eating.

\subsubsection{Analgesic Responses}

Sucrose acts as an opioid-receptor-dependent calming agent; thus, its ability to act as an analgesic has been the subject of extensive investigations in preterm and term infants, beginning with the early work of Blass and Hoffmeyer (1991). As demonstrated in a recently updated systematic review, Harrison et al., (2010), studies performed over the past 20 years have shown that sweet tastants can be effective in reducing spontaneous crying and pain in preterm and term infants during an array of painful procedures such as a heal lance, venipuncture, or intramuscular injections, with minimal to no side effects In these studies, crying, and in some cases heart rate/vagal tone, sucking, and facial grimacing, was evaluated before, during, and immediately after infants received a sweetened pacifier or drops (i.e., $0.05-0.5 \mathrm{ml}$ ) of nutritive (e.g. sucrose, glucose, or fructose) (for review, see Stevens et al., 2010) or nonnutritive (aspartame; Barr et al., 1999) sweeteners in solutions and compared to responses of infants given unsweetened pacifiers or drops of water respectively.

This body of research, as summarized in Table 36.1, has revealed that, in general, when a small amount of sweet substance is placed on the tongue of a crying infant, a rapid, calming effect ensues that persists for severa minutes, whereas no such response is observed when water or an unsweetened pacifier is administered. This reduction in crying is concordant with changes in measures of other physiological reflexes, such as heart rate and orofacial responses. Sucrose has also been shown to attenuate a negative electroencephalographic (EEG) response to a painful procedure (Fernandez et al., 2003), suggesting that sucrose blocks pain afferents, which in turn diminishes stress and cardiac changes. Because noncaloric sweet substances such as aspartame mimic the calming effects of sucrose (Barr et al., 1999), and the administration of sucrose by direct stomach loading is ineffective (Ramenghi et al., 1999), it is generally accepted that afferent signals from the mouth, rather than gastric or metabolic changes, are responsible for the analgesic properties of sweet tastes. Interestingly, such effects may be also induced by some non-sweet tasting stimuli. Thes, one study found that quinine transiently decreased crying (Graillon et al., 1997), implying that in addition to positive hedonic valence, taste salience may account for initial crying reduction It $_{\mathbf{1}}$ is presently is-unknown whether other tastes, such as salty or sour tasting agents, would produce similar analgesic effects.

\subsection{TASTE SENSITIVITY AND PREFERENCE IN CHILDREN}

The ability to reliably measure changes in the taste system throughout childhood requires a thorough understanding of developmental abilities of children at various ages so that developmentally appropriate tasks may be chosen after careful consideration of the objectives of the study and the methodological issues. There is a need for more experimental investigations of children's taste sensitivity and preference; however, a major challenge in studying children's behavioral responsivity is to identify developmentally appropriate tasks that are fun for children and that produce reliable and valid results (Mennella and Beauchamp 2008). Below we discuss some of the methodological issues to consider when designing experiments to measure taste sensitivity and preference in 2- to 16-year-old children.

When testing children, care should be taken to create a friendly and inviting atmosphere and to employ an age-appropriate experimental protocol to ensure that both the child and the parent are comfortable with the setting. Upon arrival, initial interactions with the child and parent should be devoted to developing rapport and allowing them to habituate to the testing environment. To encourage the child to engage in the testing procedure, test sessions should not begin with an unpleasant taste. It is also important to remember that children are sensitive to demand characteristics and will often alter their behavior to conform to the experimenter's expectations. 
For example, children will often answer questions in the affirmative. This can be avoided by using a forced-choice categorization procedure, which requires that they choose which solution they like better (or is more concentrated), rather than indicating whether they like (or can detect) the taste of a solution. In general, experimental tasks should be embedded in the context of games that are fun for the child and minimize the impact of language and cognitive development.

Relative to older children and adults, young children have difficulties with concept formation (e.g., sweetness) and classification (e.g., like/dislike), and because of their limited linguistic skills, they may have difficulty understanding directions or the abstract nature of symbols and pictures. Therefore, prior to actual testing and after a period of acclimation, the experimenter should ascertain whether or not the child comprehends the task. Even when children understand the task, they are more prone to attention lapses and limited memory spans, which may limit their performance. For example, 3-year-old children can understand a standardized sorting task, but only about half have the attention span to successfully complete the task. Any method relying on sustained attention that places demands on memory could yield spurious findings. For this reason, it is important to establish the reproducibility of measures over time. Unfortunately, few peer-reviewed research studies have systematically determined the validity of their methods among children of varying ages (Chambers, 2005). Moreover, only a handful of studies reviewed herein include methods to assess how reproducible and stable the child's response is over time.

In the following sections, we describe the methodologies used to measure 2- to 16-year-old children's reflex-like behaviors to tastants and the behavioral tasks performed to measure their taste sensitivities and preferences. A summary of this research is provided in Table 36.1.

\subsubsection{Reflex-like Behaviors}

36.6.1.1 Orofacial Responses. Although studies with infants have used orofacial responses to measure differential responses to the basic tastes (Rosenstein and Oster, 1988; Steiner, 1973, 1977), fewer studies have used this approach to measure hedonic responses in older children. As children mature they learn to control and manage their facial expressions to satisfy display rules that are consistent with societal norms (Ekman and Freisen, 2003; Larochette et al., 2006). Because of such emotional masking, children's attempts to conceal or exaggerate their actual responses to particular tastes may lead to biased or inaccurate data. According to Ekman and Freisen (Ekman and Freisen, 2003), although individuals attempt to manage their facial responses, micro-expressions that reflect their true emotions often "leak" into their overall expression for a fraction of a second. Although these microexpressions are difficult to measure, subtle changes in facial responses can be detected using facial electromyography, which measures the electrical activity of facial muscles and can detect movements that are too discrete for the eye. This procedure has been used to measure hedonic, emotional, and cognitive responses to tastes (Hu, Luo et al., 2000; Armstrong, Hutchinson et al., 2007; Armstrong et al., 2007; Epstein and Paluch, 1997; Hu et al., 1999, 2000). The three most commonly used muscles for detecting changes with EMG are the levator labii, contraction of which results in lifting of the upper lip (AU10) and wrinkling of the nose (AU9), and the corrugator supercilii, which furrows the brows (AU4). Both of these muscles respond strongly to unpleasant stimuli and poorly to pleasant stimuli. The third muscle is the zygomatic major muscle, which pulls up the corners of the lips (AU12) and responds strongly to hedonically positive and negative taste stimuli (Armstrong et al., 2007). Future research that incorporates the monitoring of facial expressions will provide important insights into children's sensitivity and liking of basic tastes.

36.6.1.2 Analgesic Responses. Only a few published studies have investigated whether the analgesic effect of sweet tastes extends from infancy into later childhood (Miller, Barr et al., 1994; Lewkowski et al., 2003; Pepino and Mennella, 2005b; Mennella, Pepino et al., 2010). In order to induce pain in 8- to 11-year-old children in an ethical manner, these studies have used the cold pressor test in which participants submerge a forearm in a cold water bath (10 degrees Celsius) while holding either equal volumes (15-20 ml) of water or 24\% sucrose solution in the mouth $_{\text {k }}$

Such studies have demonstrated that the pain threshold (the time in seconds at which discomfort was first indicated by raising the non-immersed hand) and pain tolerance (the number of seconds the hand was kept in the cold water) are both increased when children hold sucrose, but not water, in the oral cavity (Mennella et al., 2010b; Miller et al., 1994; Pepino and Mennella, 2005b). Interestingly, sucrose's efficacy in reducing pain threshold and tolerance was related to the hedonic value of sweet taste for the child: the more a child liked sucrose, the more tolerant the child was of the pain of the cold water while tasting sucrose (Mennella et al., 2010b; Pepino and Mennella, 2005b). Further work has demonstrated that children who have depressive symptomology report eating more sweet-tasting foods than do those who are not depressed; however, they had similar pain thresholds regardless of whether they held sucrose or water in the mouth during the cold pressor task, demonstrating that sucrose is an ineffective analgesic for these children (Mennella et al., 2010b). Thus, it appears that depression antagonizes the analgesic properties of sucrose. 


\subsubsection{Behavioral Methodologies for Measuring Taste Sensitivity and Preference}

36.6.2.1 Paired-Comparison and/or

Forced-Choice Procedures. In older children, it is possible to use methods that do not confound sensitivity and hedonics. Often these methods involve forced choice, a procedure that requires respondents to compare two or more options and choose one. In taste studies with children, forced-choice procedures often involve the presentation of a series of trials that present solutions that vary in concentration of a particular tastant. Each of the solutions in the series may be presented alone, in which case the children are asked to indicate whether they can detect or like the tastant in each sample. Alternatively, each solution may be paired with another solution (e.g., the diluent, or another concentration of the tastant). In these studies children are asked to compare the solutions on each trial and to choose which they like best (preference), or which contains the tastant under study (sensitivity). In some cases, especially when the subject population consists of children younger than 5 years, this forced-choice task is embedded in the context of a game (Mennella et al., 2005; Schmidt and Beauchamp, 1988) or story (Visser et al., 2000). In general, forced-choice, paired-comparison procedures, unlike tests where the subject is required to remember sequentially presented stimuli to make relative judgments, are especially useful for young children because memory requirements are minimized. Below we highlight some examples of procedures that have utilized these methods.

Using a forced-choice procedure that was presented in the context of a game, Mennella et al. (2010a) determined children's sensitivity thresholds to 6-n-propylthiouraci (PROP). Based on the procedures of Anliker et al. (1991), children were presented, in succession, with samples of water and then three increasing concentrations of PROP $(56,180$, and $560 \mu \mathrm{M})$ and asked to taste the sample without swallowing. If the solution tasted like "water" or "nothing," then they were asked to give the sample to Big Bird, a popular television character. If the sample tasted "bad," "yucky," or "bitter," children were asked to give it to Oscar the Grouch so he could throw it in his trash can Children were classified into groups based on the concentration of the first sample, if any, that was given to Oscar the Grouch. This research has shown that children who are heterozygous at the TASR 38 gene locus are more sensitive to taste of PROP than were heterozygous adults, with the thresholds of heterozygous adolescents being intermediate (Mennella et al., 2010b), whereas homozygous children and adults did not differ in threshold. This task is one of the few that has been shown to be reliable ( $>85 \%$; (Mennella et al., 2005) and valid, with $76 \%$ concordance between genotype and phenotype (Keller et al., 2010), and is effective for children as young as 3 years of age (Mennella et al., 2010a).

In other studies, children were presented with a series of pairs of solutions, with one member of the pair being water and the other containing an aqueous tastant (i.e., paired comparisons). In some cases the aqueous tastants increased in concentration with each pair presented, and the child was required to indicate which sample of the pair contains the tastant, or tasted stronger. The lowest concentration that was detected successfully in one or two consecutive trials was recorded as the detection threshold (James et al., 1997). In other cases, the concentration of the tastant in each pair was determined by the child's ability to detect the tastant in the previous pair of samples. For example, in the staircase procedure, if the child incorrectly indicated which sample contained the tastant, in the next trial the next stronger tastant solution was presented; if the child was correct, a second presentation with the same concentration was given (Anliker et al., 1991).

A similar procedure, called the forced-choice tracking procedure, has been adapted to assess suprathreshold concentrations of tastants. In these studies, participants are instructed to taste, without swallowing, each solution and then to point to which of the pair they like better (or tastes stronger). For example, Mennella et al. (2011b) presented children with pairs of sucrose solutions that differed in concentration $(3-36 \%)$. They were first presented with a pair of samples chosen from the middle range $(6 \%$ vs. $24 \%$ ) and were asked to taste each without swallowing and then to point to which of the pair they liked better. Like the staircase procedure described above, each subsequent pair was then determined by the subject's preceding preference choice. The procedure continued until the subject either had chosen a given concentration of sucrose when it was paired with both a higher and lower concentration or had chosen the highest $(36 \% \mathrm{w} / \mathrm{v})$ or lowest $(3 \% \mathrm{w} / \mathrm{v})$ sucrose solution two consecutive times. The entire task was then repeated with stimulus pairs presented in reverse order (e.g., weaker stimulus presented first in series 1; stronger stimulus first in series 2), thus preventing children from reaching criterion response based on bias toward first or second position. The geometric mean of the two sucrose concentrations chosen in series 1 and 2 estimated the participant's preferred level of sucrose.

By comparing the solution chosen in the first and second (reverse-order) task, one can achieve reliable results within each participant. As reviewed in Table 36.1, this procedure has been shown to be sensitive enough to examine individual differences (e.g., race, age, genetic) in sweet and salt taste preferences in children as young as 5 years of age and how differences in preferences relate to a variety of factors, including analgesia, obesity, dietary habits, and depression (Cowart and Beauchamp 1990; Mennella et al., 2010b, 2011b, 2005; Pepino and Mennella 2005a). 
36.6.2.2 Scaling Techniques. Various types of scaling methods, that is, methods in which sensations to varying concentrations of suprathreshold stimuli are quantified, have been used to determine children's preferences and sensitivity to tastes. Depending on the child's age, these procedures involve presenting the child with a line or other type of scale that contains pictorial or verbal descriptors in a graded order. Although there has been no systematic determination of what scaling test is most appropriate for children at what age, some researchers have concluded that use of scales in children younger than 5 years can be problematic because they have not mastered the ability to rank things in order of magnitude (Guinard, 2001).

For children as young as 3 years of age, researchers typically use hedonic rating scales. Depending on the age of the child, these scales can consist of two to nine faces where one of the anchors is a happy face and the other is a frowning face. While the increase in the number of faces potentially allows for finer-grain analyses of children's hedonic responses, preschool children do not appear to be able to reliably use scales that contain more than five faces (Chen and Resurreccion, 1996). However, little is known about the validity and reliability of these scales and at what age children begin using the entire scale rather than the anchors only.

Due to this gap in our knowledge about the use of hedonic face scales with children, researchers typically use them in combination with other measures. For example, when de Graaf and Zandstra (1999) tested the pleasantness of sucrose $(0.03-0.88 \mathrm{M})$ in water and in orangeade in 9- to 10-year-old children, adolescents, and adults with a 5 -point hedonic face scale, they found ratings of pleasantness correlated moderately with intake, and the strength of these correlations increased with age. The authors suggest that the increasing reliability observed with increasing age could be related to the development of cognitive capacity, which allowed older children to more consistently process and code the sensory information.

In addition to hedonic face scales, researchers have used other scales that include verbal descriptors (ranging from "no taste" to "very strong taste" (Anliker et al., 1991), and in some cases these verbal descriptors have been used with the Labeled Magnitude Scale (Coldwell et al., 2009). Here, children are shown a visual analog scale labeled with "barely detectable," "weak," "moderate," "strong," "very strong," and "strongest imaginable" and are asked to compare the intensity of each taste to oral sensations of any kind. Typically participants are trained on this scale by asking them to rate examples, including the sweetness of cotton candy, the bitterness of celery, or biting into a raw lemon or chili pepper. Although the use of verbal descriptors appears to be effective for measuring sensitivity in 9- to 10-year-old children (Coldwell et al., 2009; Graaf and Zandstra, 1999), younger children may require a more concrete activity to visualize these descriptors. This has been done by asking children to place a ball into buckets that are placed at different heights to exemplify increasing taste intensities (Anliker et al., 1991; Turnbull and Matisoo-Smith, 2002). Despite gaps in knowledge about the reliability and validity of scaling techniques, there is some evidence that reliable results can be obtained from children if care is taken to use developmentally appropriate scales.

36.6.2.3 Rank Order. In rank-order methods, the goal is either to determine the child's most preferred concentration from a series of solutions, or to place all of the solutions in order of preference or stimulus intensity. In some cases children may be asked to taste all of the solutions in random order, after which they are asked to point to the one they like best (sweet preference inventory). This procedure has been used to determine whether children who chose higher concentrations of sucrose in tea have more dental caries (Jamel et al., 1997; Maciel et al., 2001a,b; Tomita et al., 1999). Their results suggest that socioeconomic status mediates the relationship between taste preference and number of dental caries in 4- to 6-year-old children (Tomita et al., 1999). However, one weakness of this methodology, which may limit the sensitivity of their results, is that children are required to remember and track a series of solutions in order to indicate their preferences, which may be difficult for preschool children.

Other approaches that are less cognitively demanding employ paired-comparison techniques in which all possible pairs of samples are presented and children are asked to choose which they prefer or which tastes stronger in each pair (e.g., Liem and Mennella, 2003). In a similar paradigm called rank by elimination, the sample that is selected from a pair in a trial is removed from the set, and children are asked to taste the remaining samples again and to point to the sample they like best or that tastes strongest. This procedure continues until a rank-order preference or intensity is established. Liem and Mennella (2003) used this procedure to determine sour preferences and sensitivity. A series of four citric acid $(0.00-0.25 \mathrm{M})$ samples prepared in a gelatin base were tasted without swallowing by 5 - to 9 -year-old children and their mothers. They pointed to the sample that they liked best during trials of one session, and the sample that tasted most sour during trials of another session. This study demonstrated that children who showed preferences for higher sour concentrations were more likely to report that they had tried and liked sour candies compared to those who preferred lower concentrations of citric acid in gelatin. These findings are consistent with other research that has shown that preference for sour taste is correlated 
with intake of fruits in infants (Blossfeld et al., 2007) and with previous consumption of protein hydrolysate formulas (Liem and Mennella, 2002) in 4- to 5-year-old children.

Other studies have used a bifurcated approach in which children are first asked to place the sample into either a "good/like" or a "bad/dislike" category. The degree to which they like the stimuli is determined using forced-choice methods, in which the children are presented with pairs of stimuli from each of the categories and asked to indicate which sample in the pair they prefer. This methodology has been used with children as young as 4 years of age to rank preferences to various foods with added sugar or salt (Sullivan and Birch, 1990), including sweetened beverages (De Graaf and Zandstra, 1999; Liem and de Graaf, 2004; Liem et al., 2004). It is importan to note, however, that like the procedures previously discussed, little work has been done to validate ranking procedures with children.

36.6.2.4 Stimulus Presentation Methods When testing children, it is important to consider the method of presentation of the taste stimuli to the tongue. Studies in which evaluation of taste solutions were directly applied to small portions of the tongue versus the whole mouth have revealed inconsistencies in sucrose sensitivity in children relative to adults. Whereas children demonstrated high sucrose sensitivity relative to adults in local anterior regions (Temple et al., 2002b), this pattern of results was not observed when a whole-mouth procedure was used (James et al., 1997). These findings suggest that taste information may not be integrated as efficiently peripherally and/or centrally in children relative to adults. Moreover, research has shown that different regions of the tongue follow different patterns of growth throughout development: growth of the posterior region continues until approximately 15 years, wherea the fungiform-papilla-rich anterior region of the tongue attains adult size by the time children are $8-10$ years of age (Temple et al., 2002a). Cessation of growth of the anterior region of the tongue by mid-childhood, however, does not mean that the anatomy and functionality of this region have reached adult levels of functioning In a series of studies using videomicroscopy, Laing and colleagues have shown that in 8- to 9-year-old children, fungiform papillae and taste pores are smaller, papillae are rounder and more homogeneous in shape (Segovia et al., 2002), and the densities of fungiform papillae and taste buds are significantly higher compared to adults (Stein et al., 1994). As a result of the uneven pattern of growth of the tongue, care must be taken not to generalize evaluation of taste solutions directly applied to smal portions of the tongue to other regions, which may be at a different stage of anatomical growth and function. This could lead to misperceptions regarding children's taste sensitivity.

\subsection{IMPLICATIONS}

\subsubsection{Children's Different Sensory} Worlds

Findings from experimental research during the past century, and especially in the past 20 years, have revealed that age is a particularly good predictor of individual differences in taste preferences. The convergence of findings from basic research reviewed herein reveals that children live in different sensory worlds than adults, preferring sweeter and saltier (and in some cases more sour) tastes than do adults and more intensely disliking bitter tastes. There is a striking paucity of research on umami taste in children; whether there are age-related changes, as observed for the other four basic tastes, remains unknown.

Further support for the concept that such hedonic responses are innate is suggested by research that has observed neonates within a couple hours of birth before their first feeding (Rosenstein and Oster 1988-Steiner, 1987). Such responses persist throughout childhood and influence dietary behaviors.- For example, children generally dislike bitter-tasting foods such as leafy green vegetables, and as a result fewer than $15 \%$ of children between the ages of 4 and 8 years consume the recommended levels of vegetables (Guenther et al., 2006). Such responses are due in part to their genotype, which is related to their acceptance of a variety of foods (e.g., broccoli, brussels sprouts, cabbage) that contain bitter-tasting moieties such as glucosinolates. However, regardless of their genotype, just as children's responses to salt and sweet are influenced by early experiences, so are children's responses to bitter-tasting foods. Through repeated exposure to bitter-tasting foods, and to a variety of other foods from an early age, they can learn to like the taste of these once disliked foods. This has been demonstrated in infants who have been exposed to bitter-tasting protein hydrolysate formulas throughout infancy. Relative to those infants who had been fed milk-based formulas, these infants consumed more of and showed fewer orofacial responses of distaste to a bitter-tasting food (Mennella et al., 2009). This inherent plasticity of the chemical senses, which serves to mediate the effects of genetics through maturation and experience, ensures that we are not restricted to a narrow range of foodstuffs by virtue of a few preferences for or strong aversions to foods.

Although children are also born with an innate distaste for sour tastes, for some children this initial negative 
$\phi$

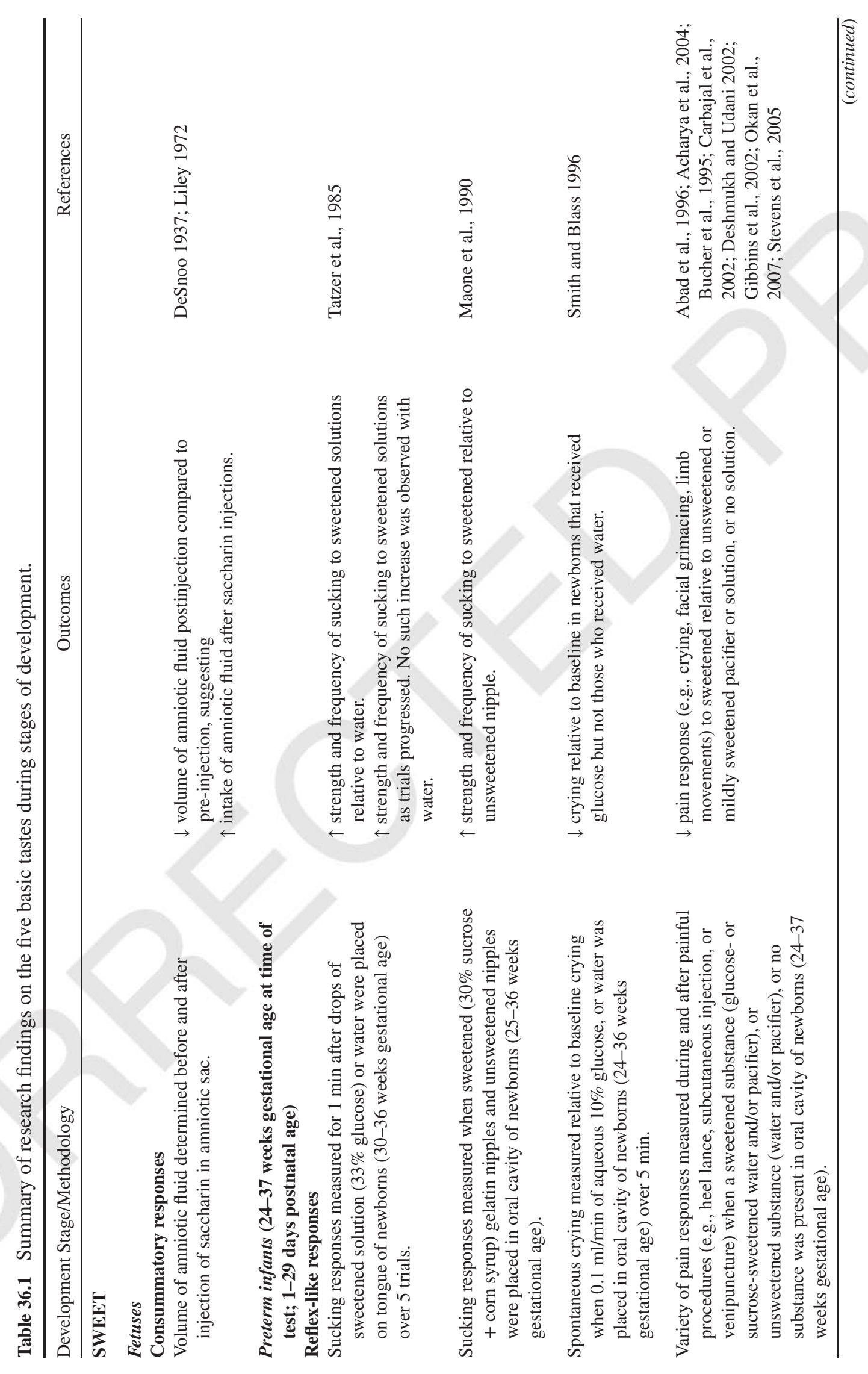




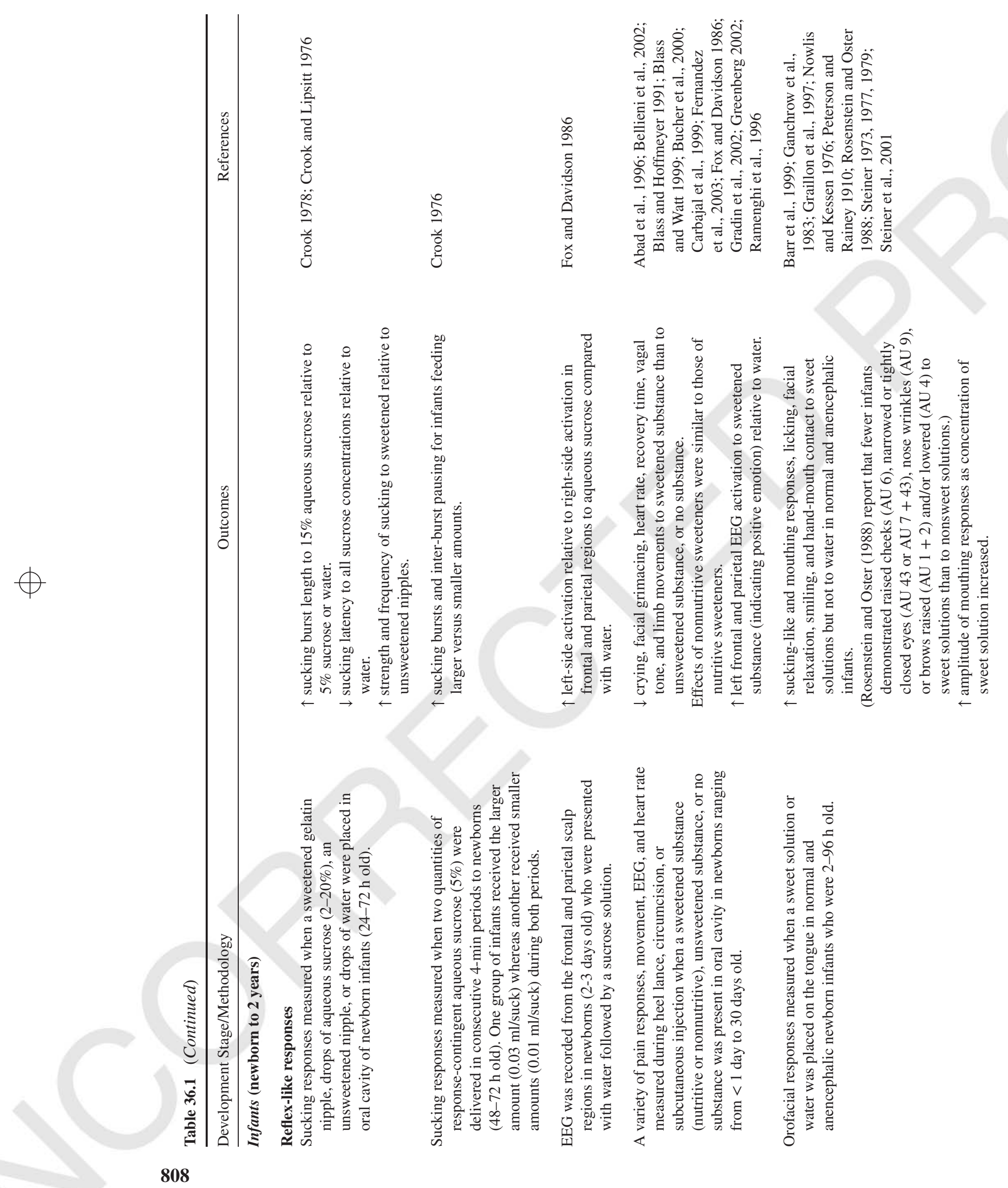



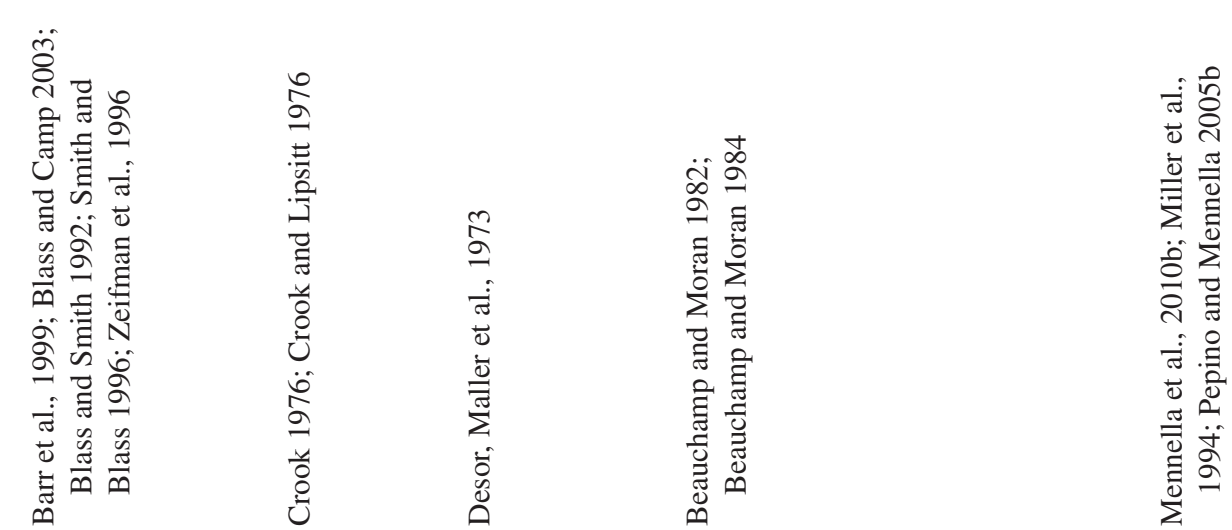

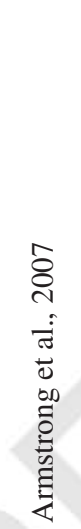

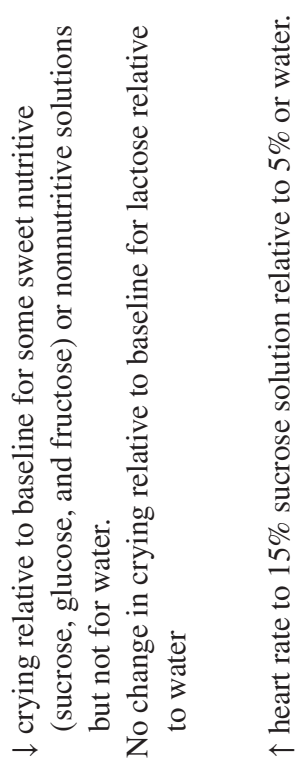
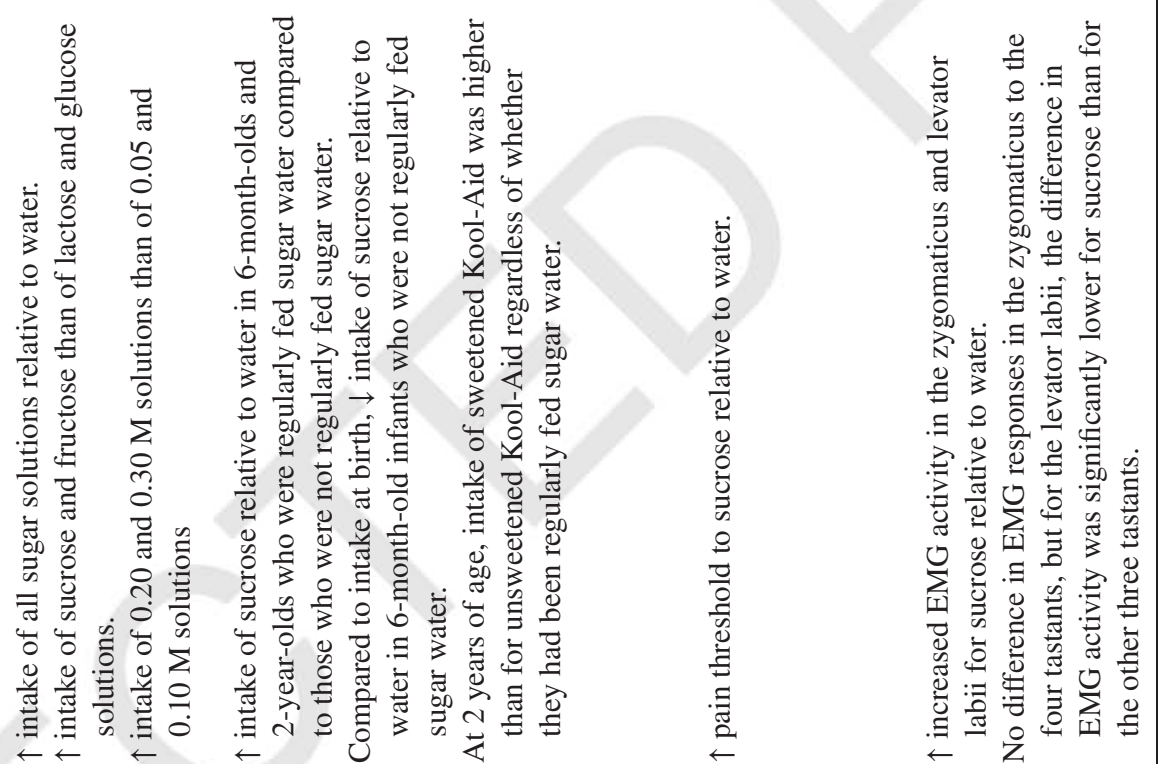

$\emptyset$
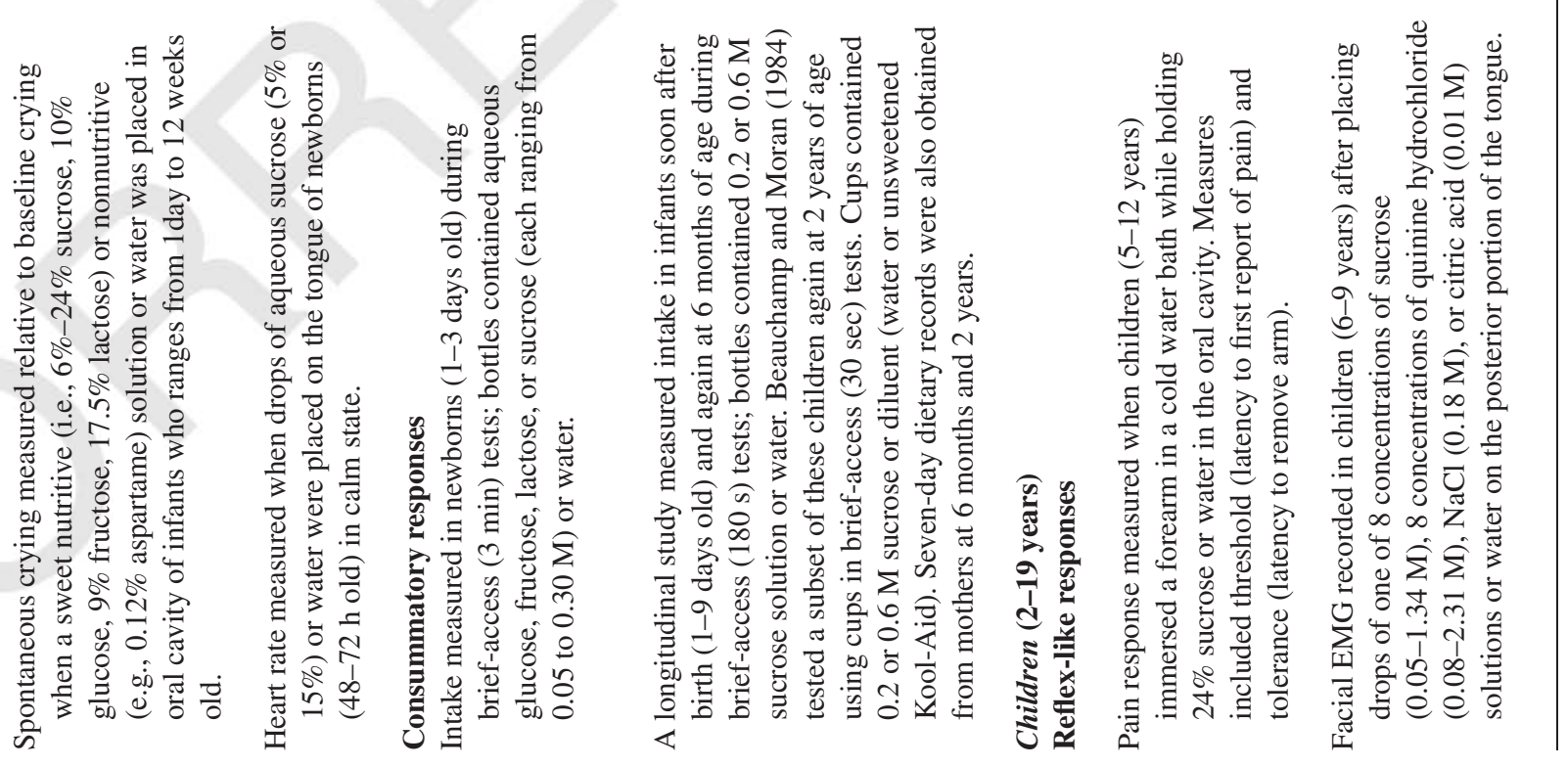

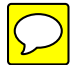




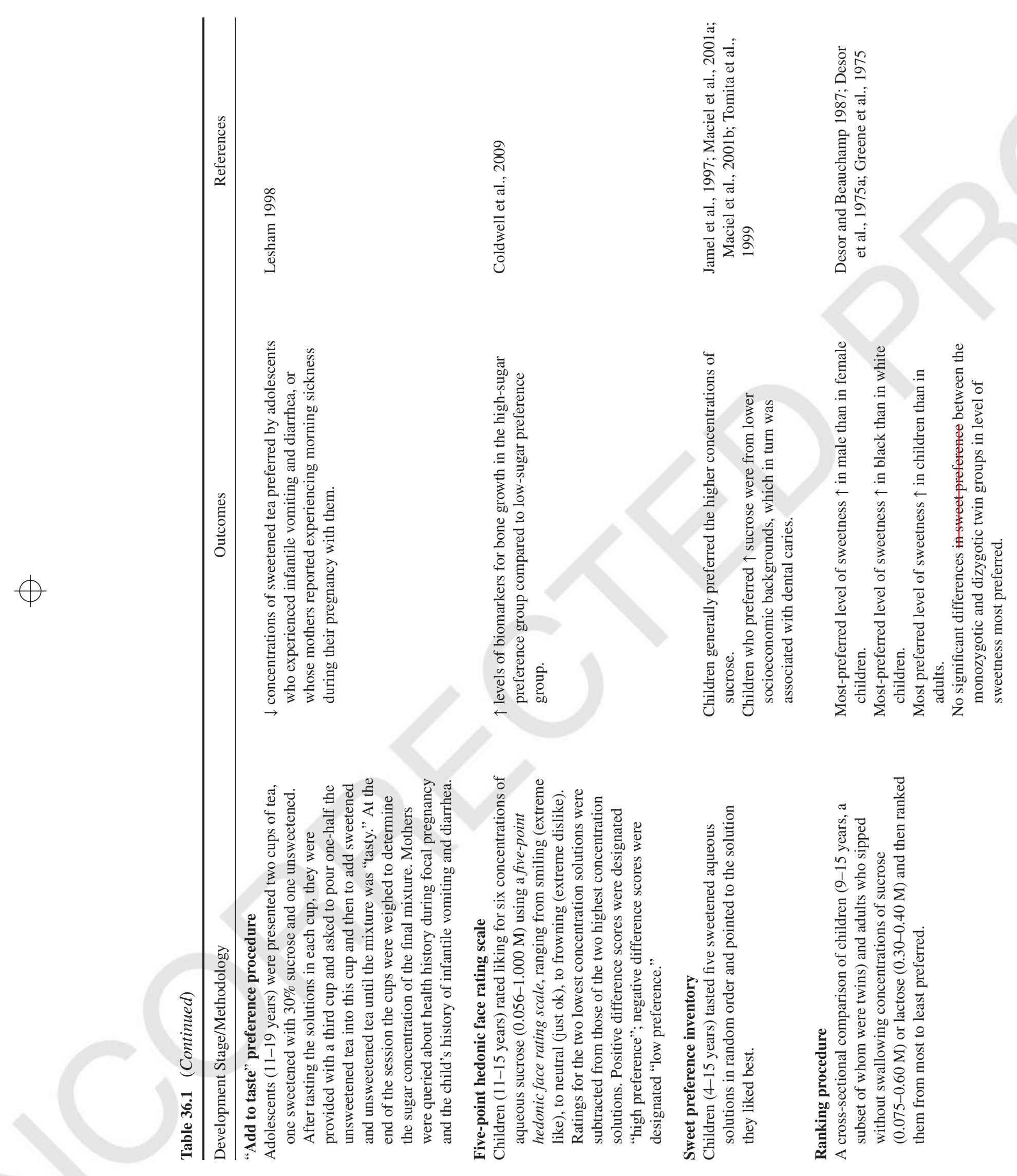



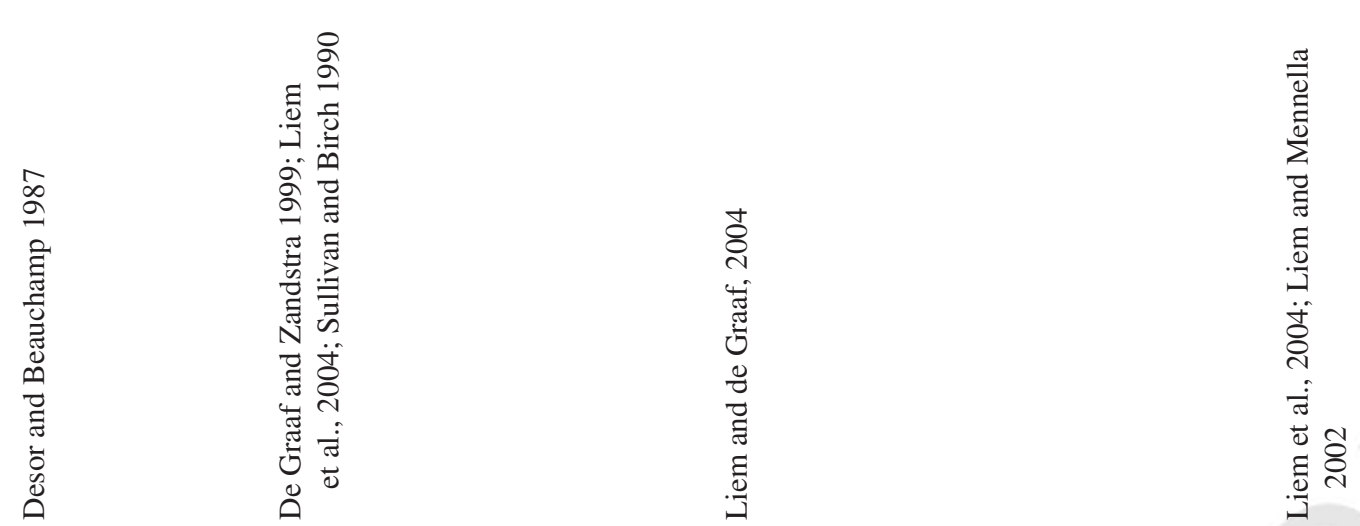

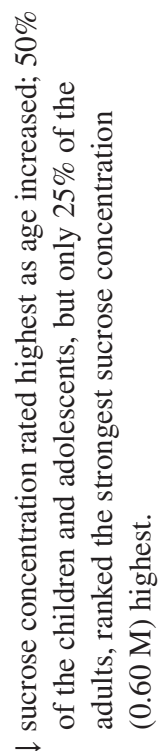

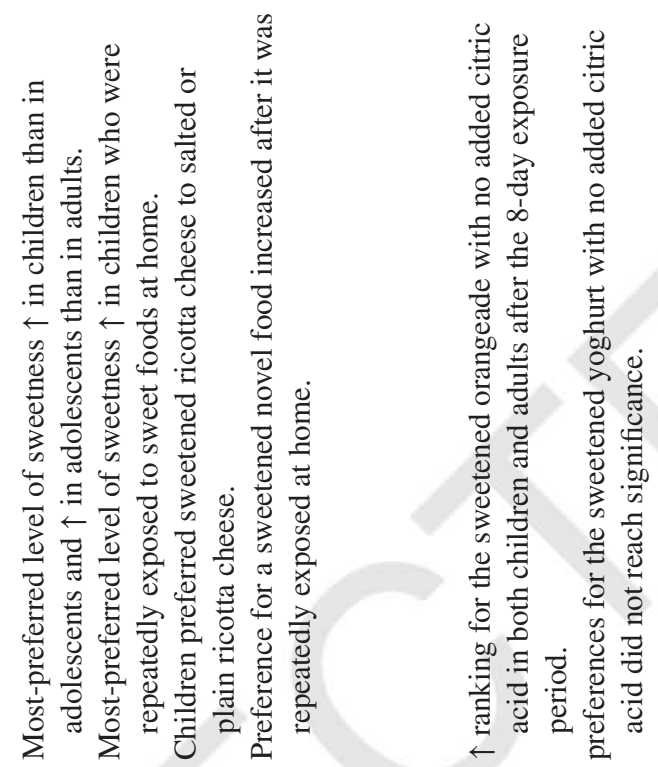

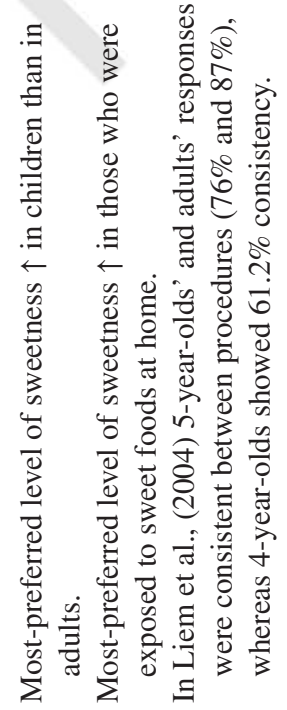

$\phi$

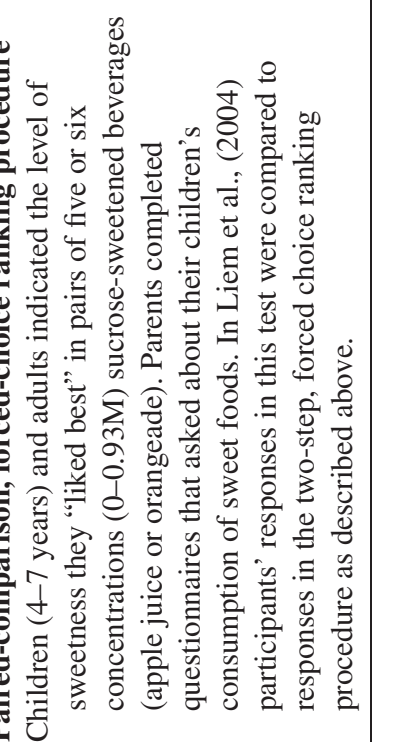




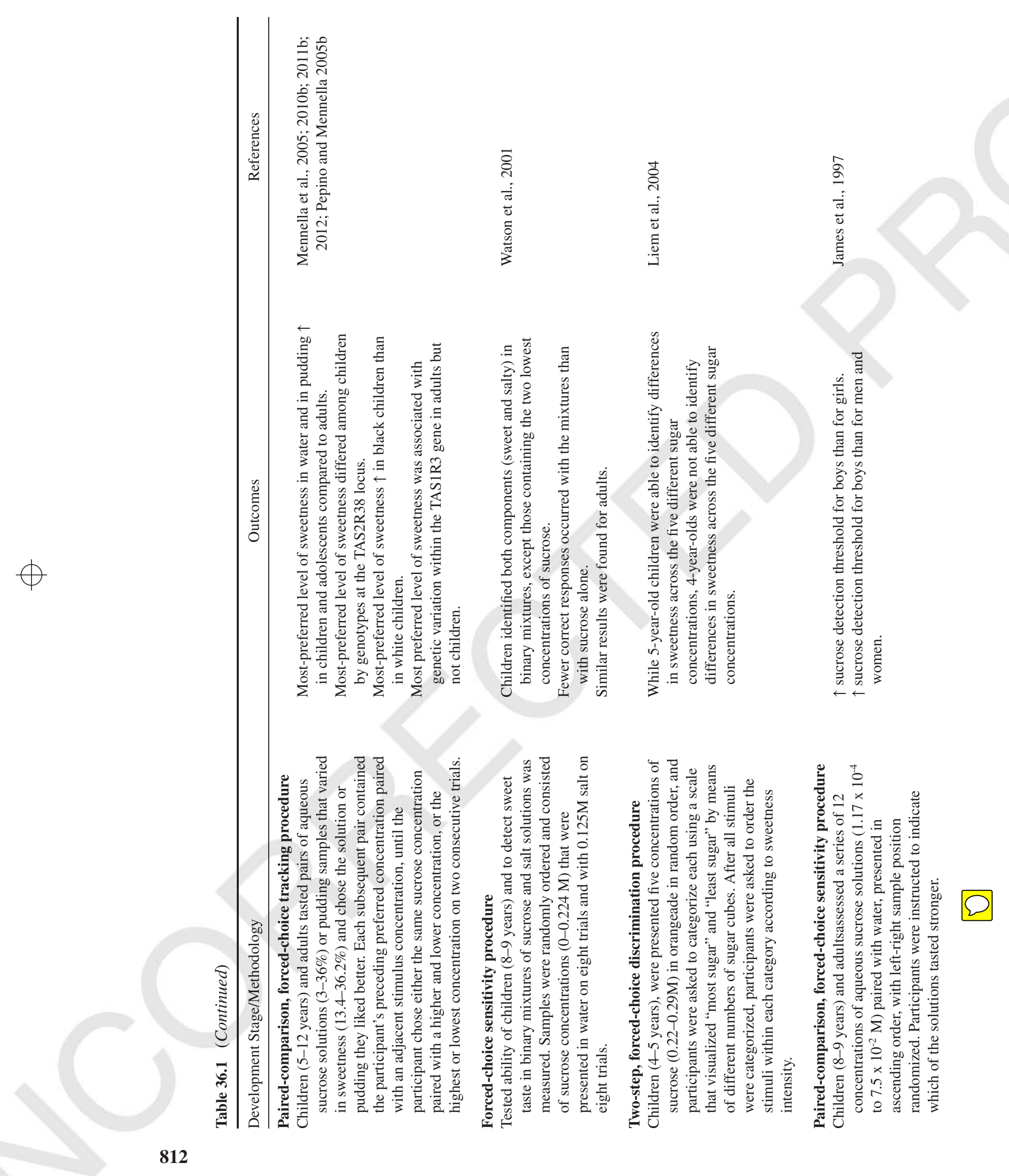


$\phi$
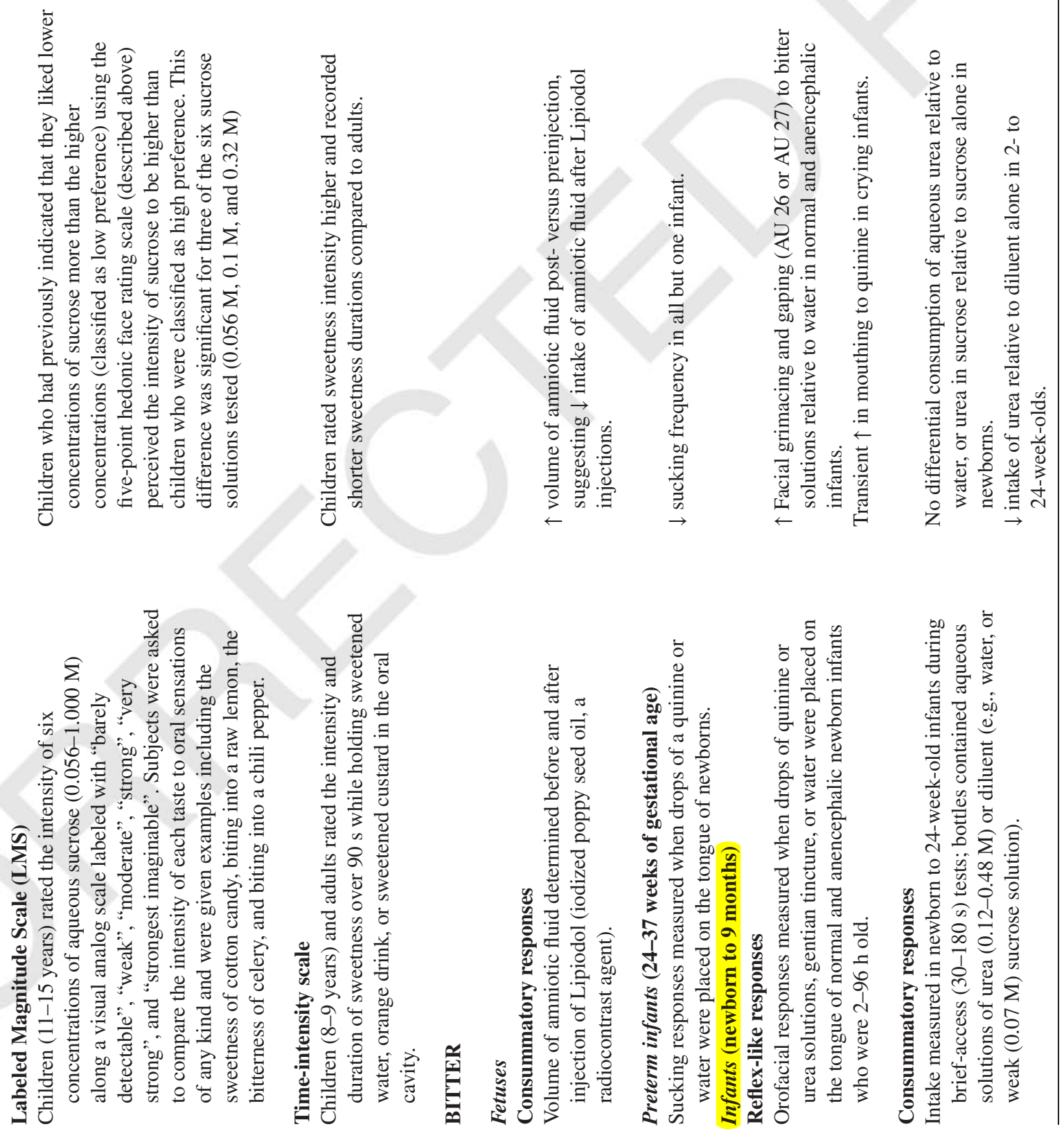

0 


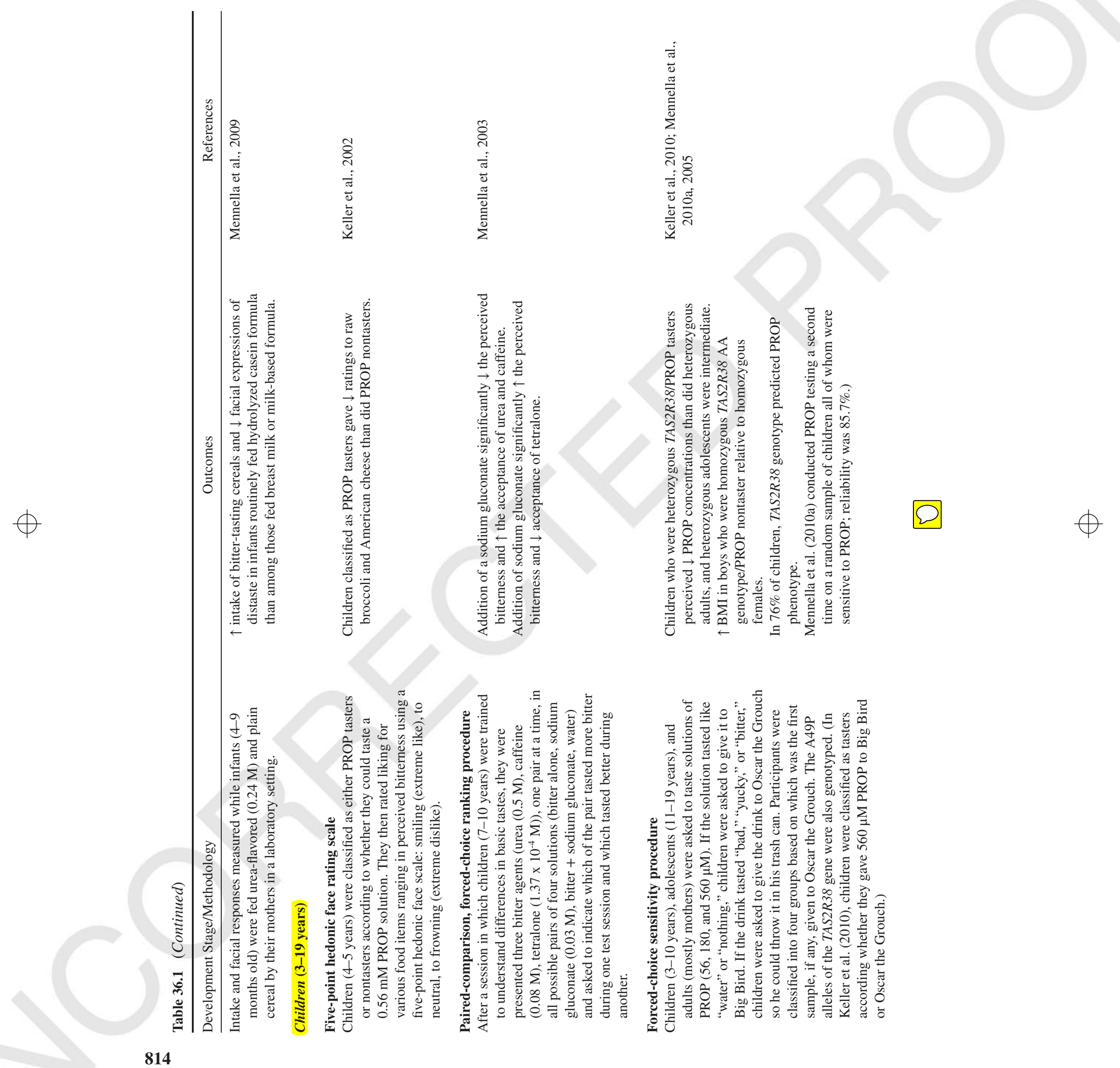




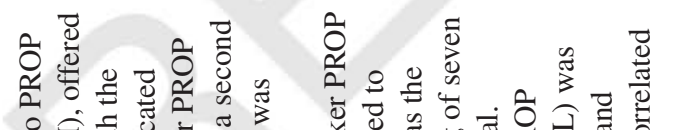

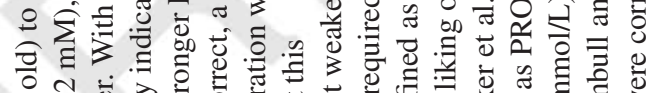

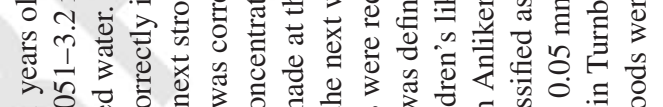

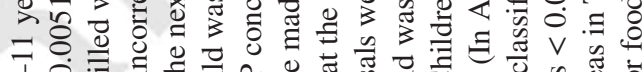

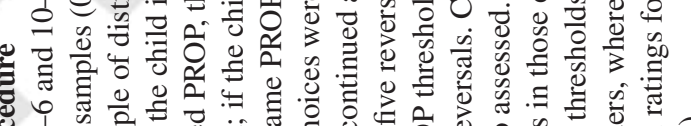

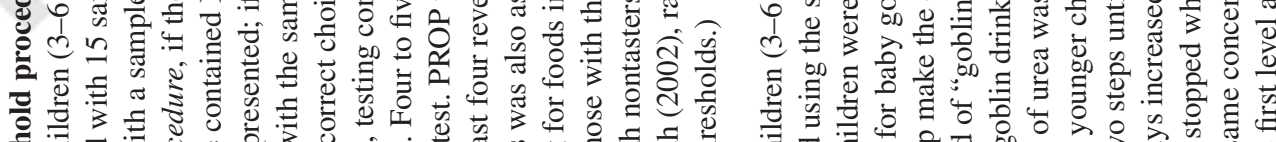

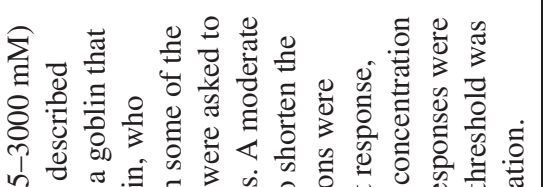
15.

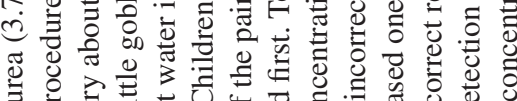

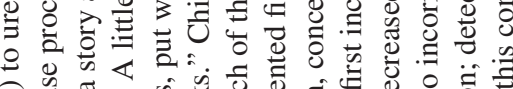

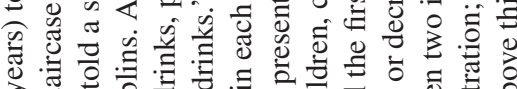

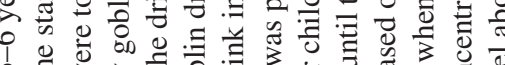

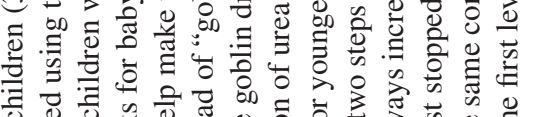

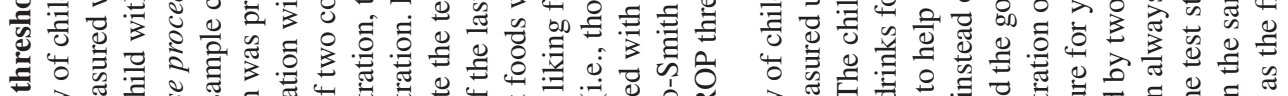

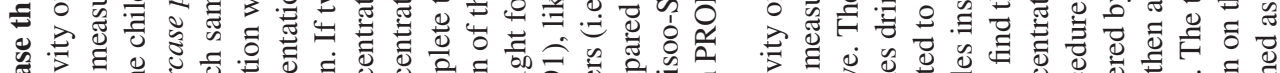

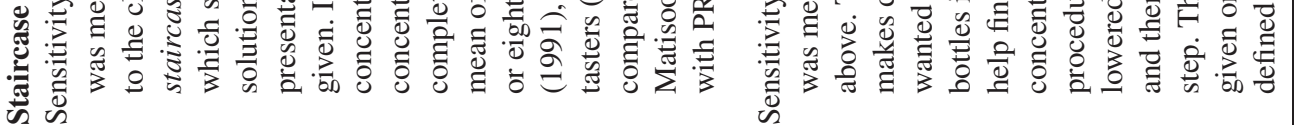
D 


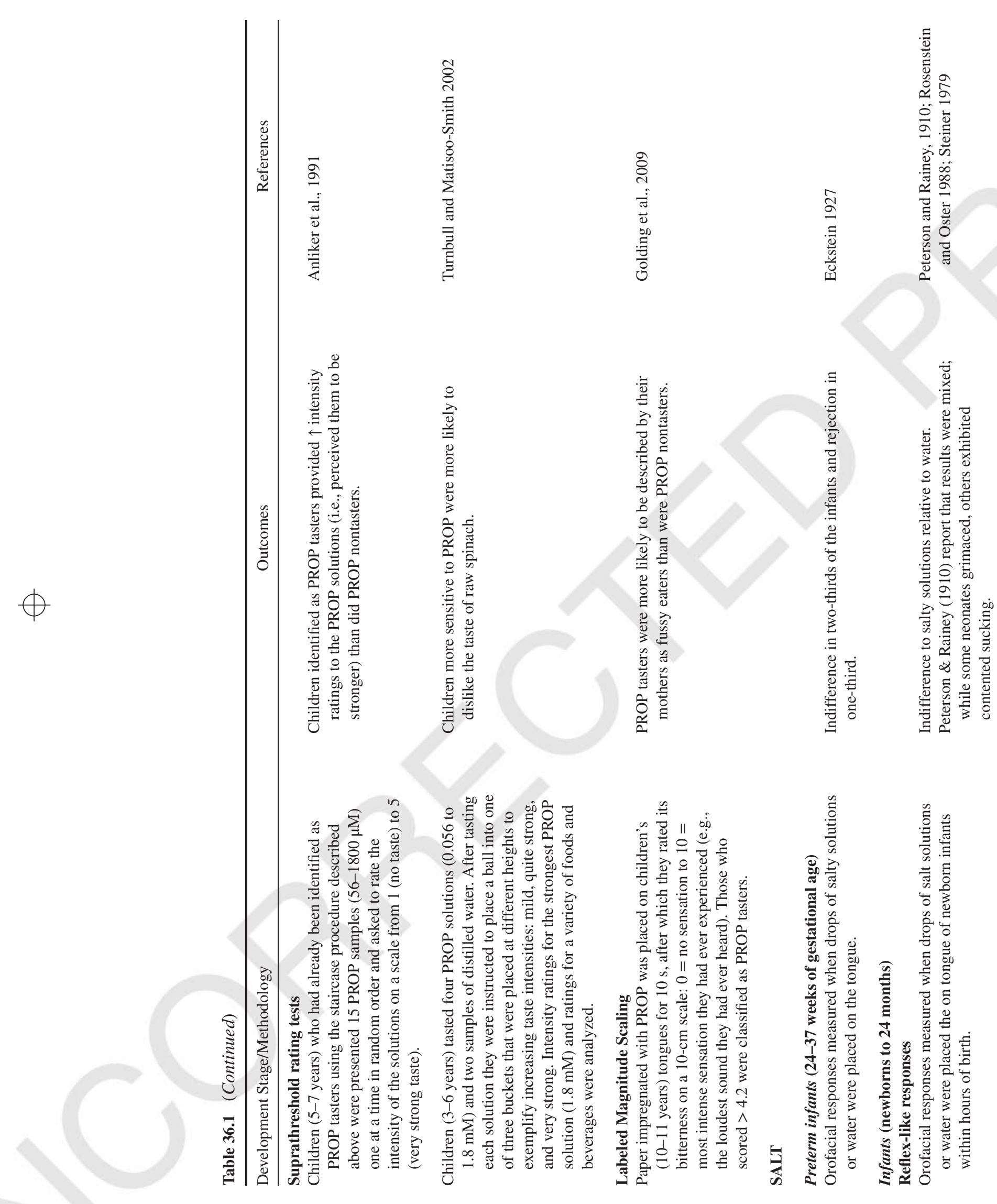



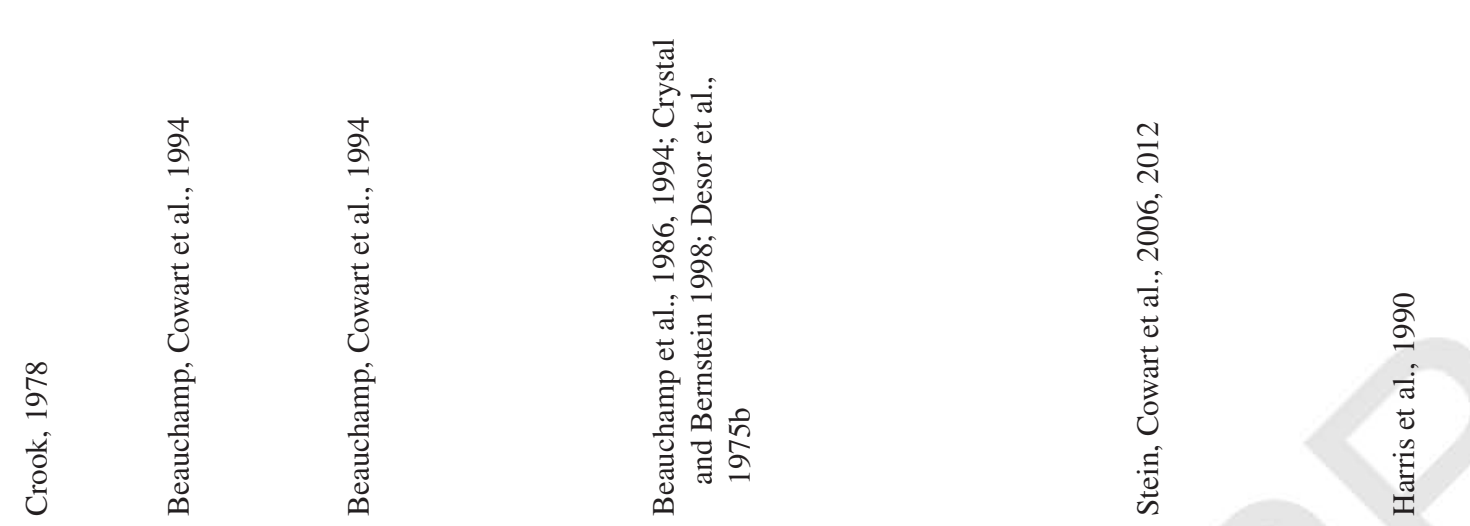

$\phi$

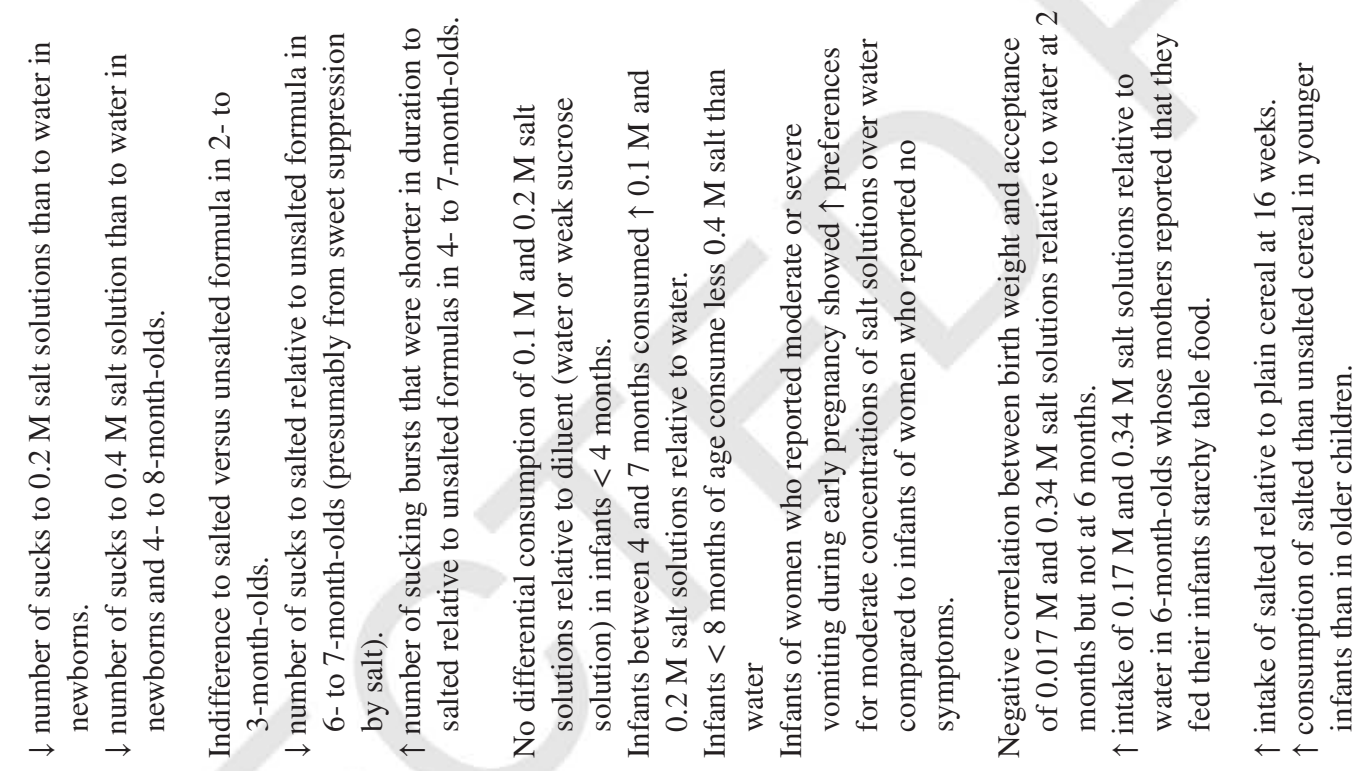

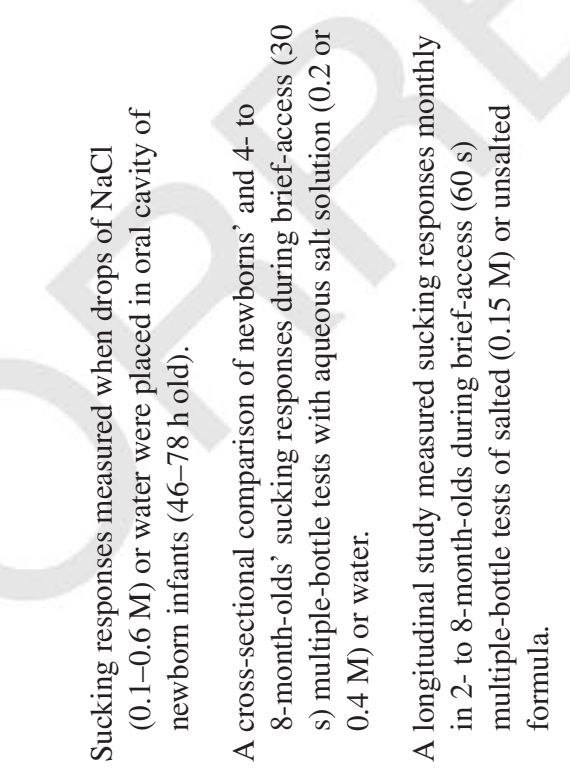

D
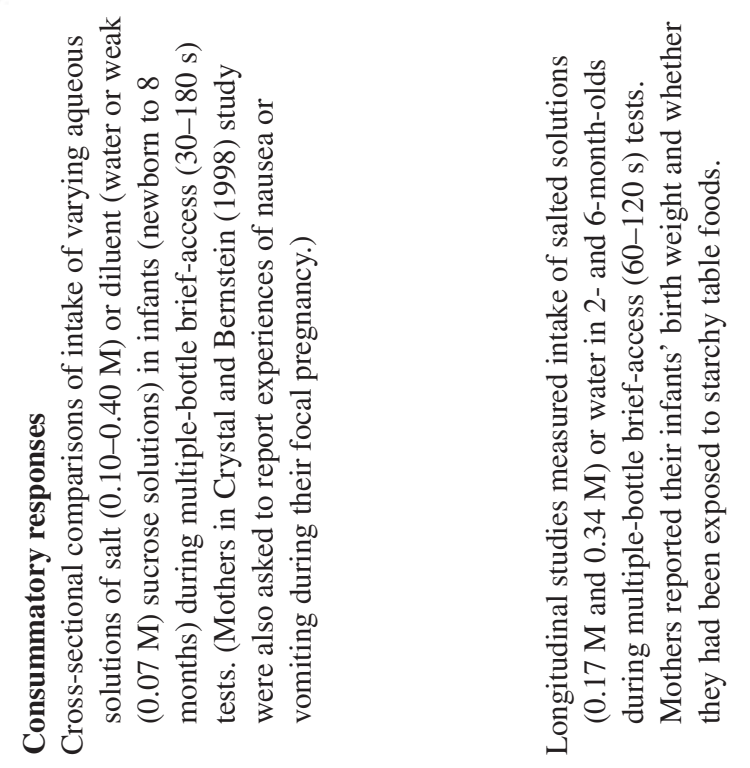

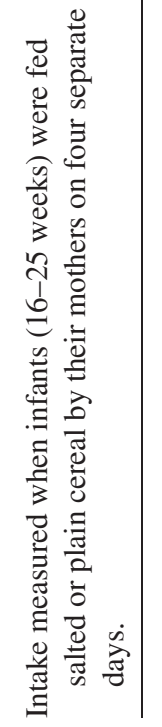




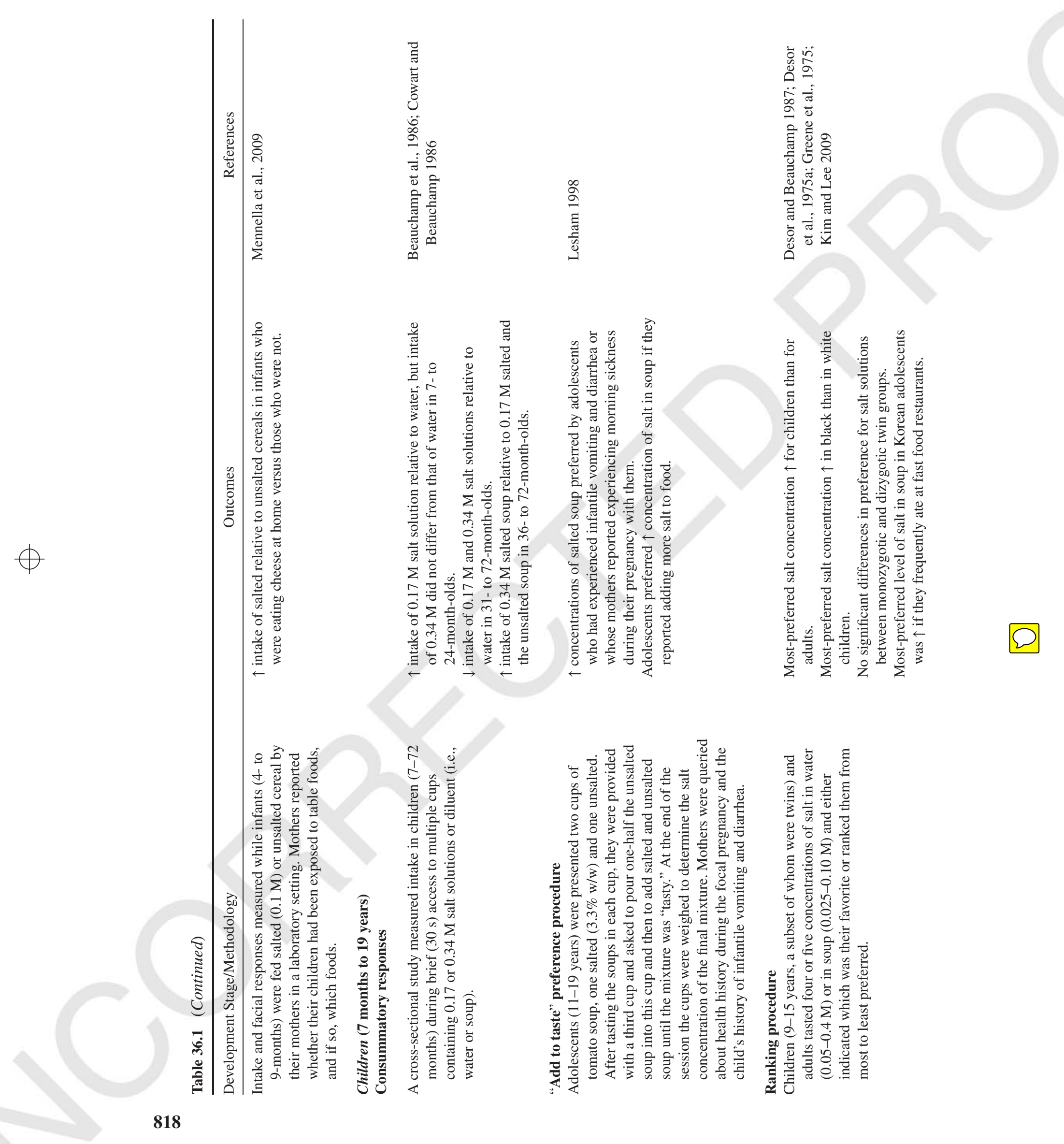




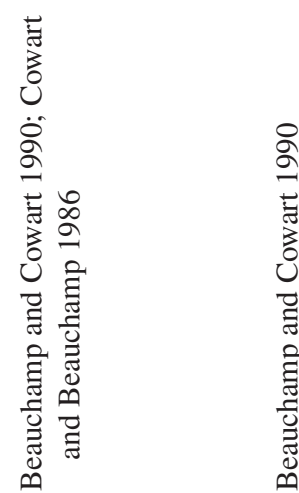

$\phi$
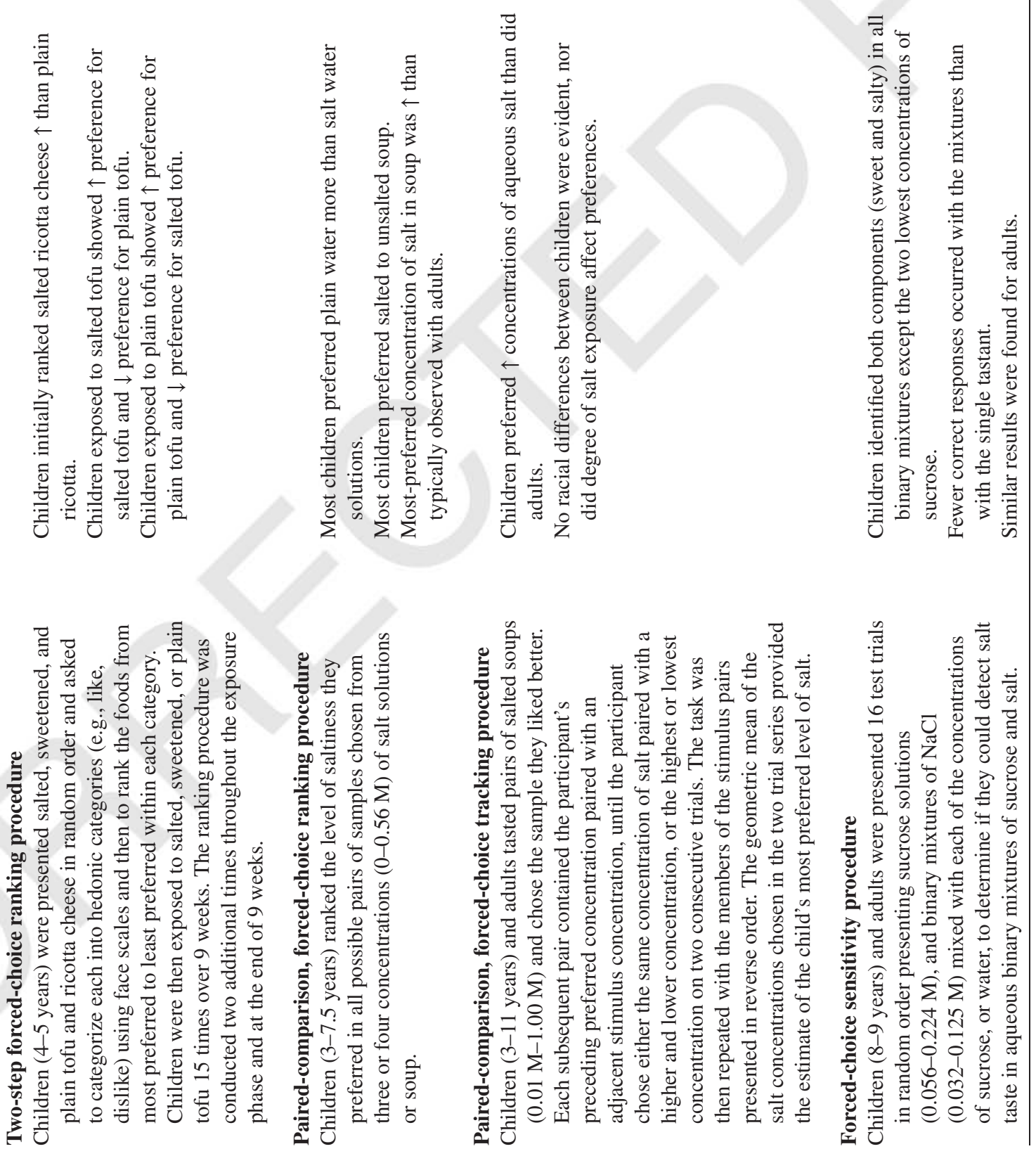

D 


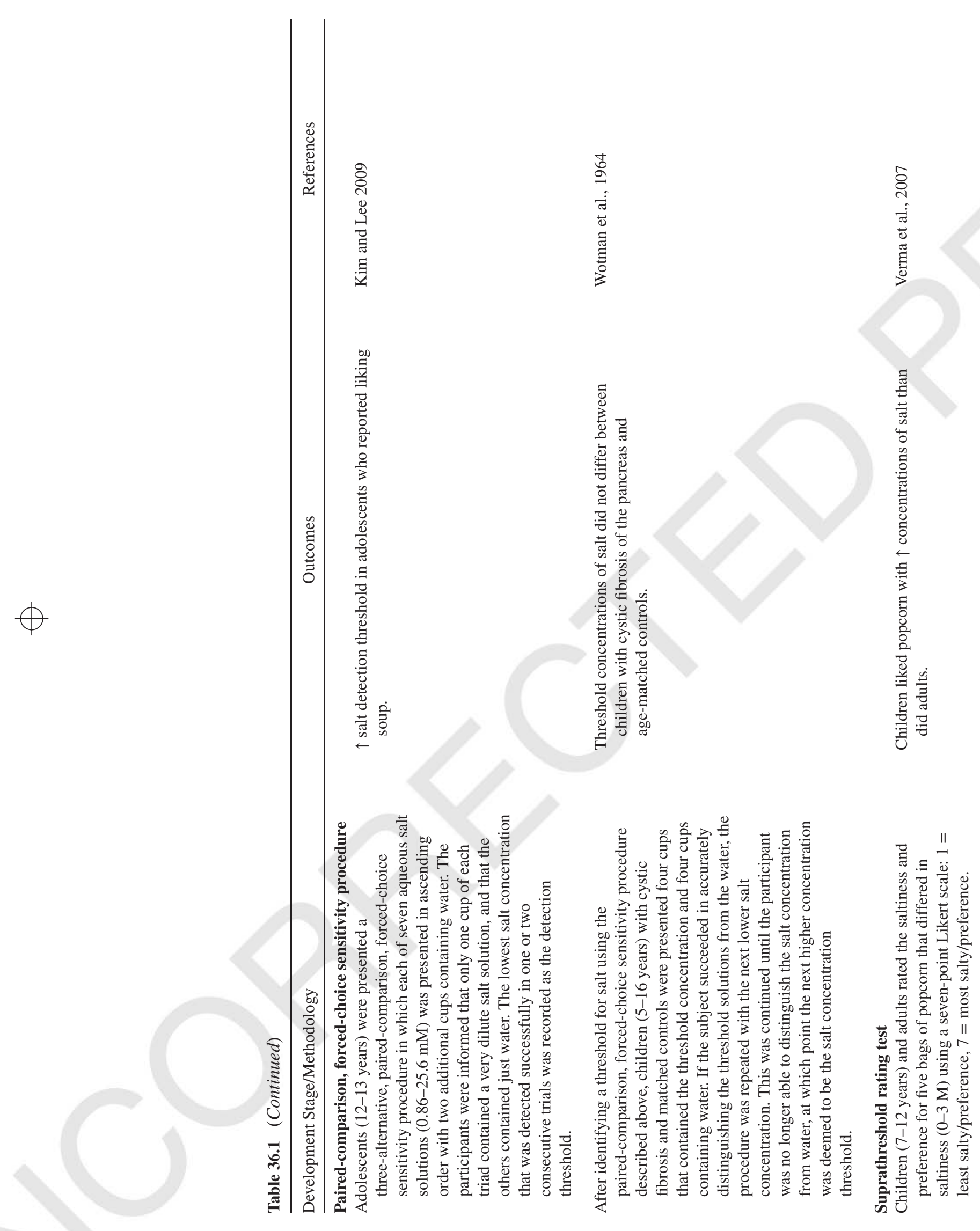


$\phi$
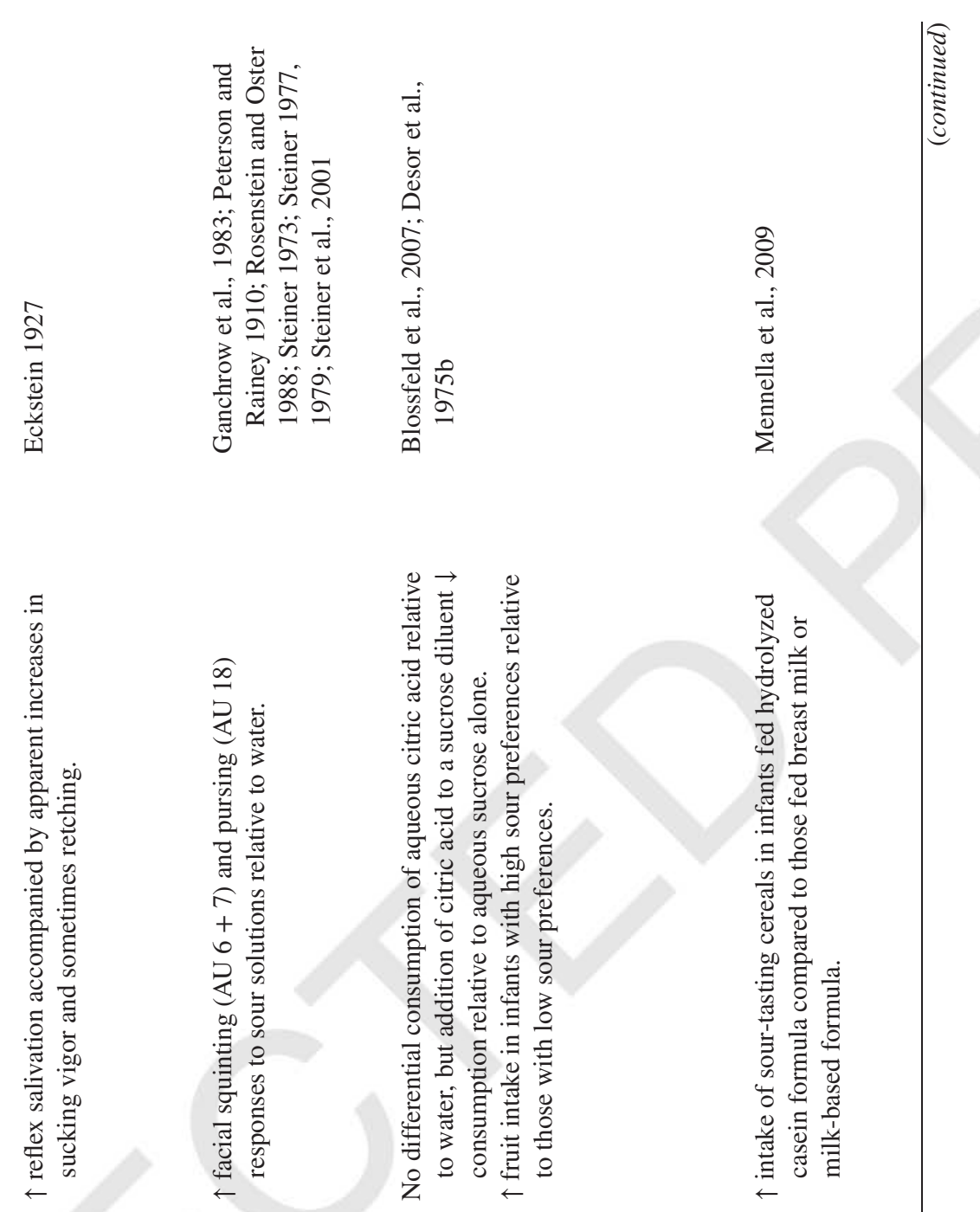

$\emptyset$

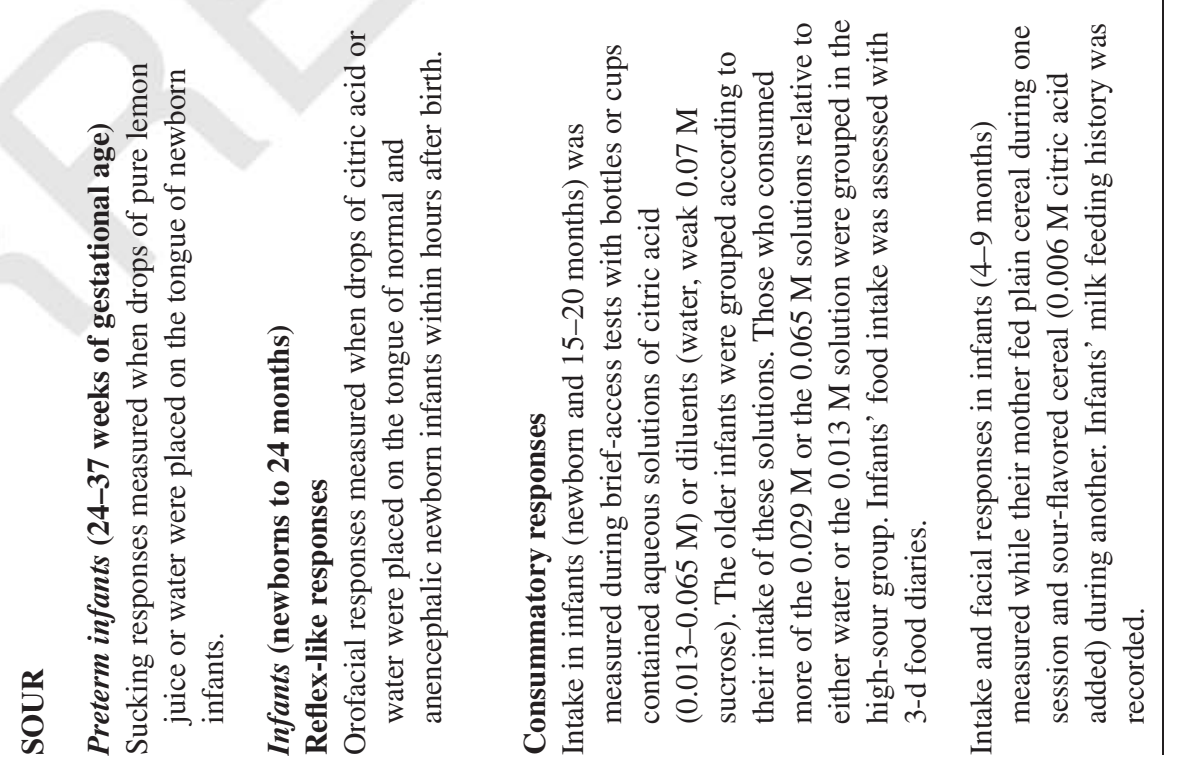

(2) 


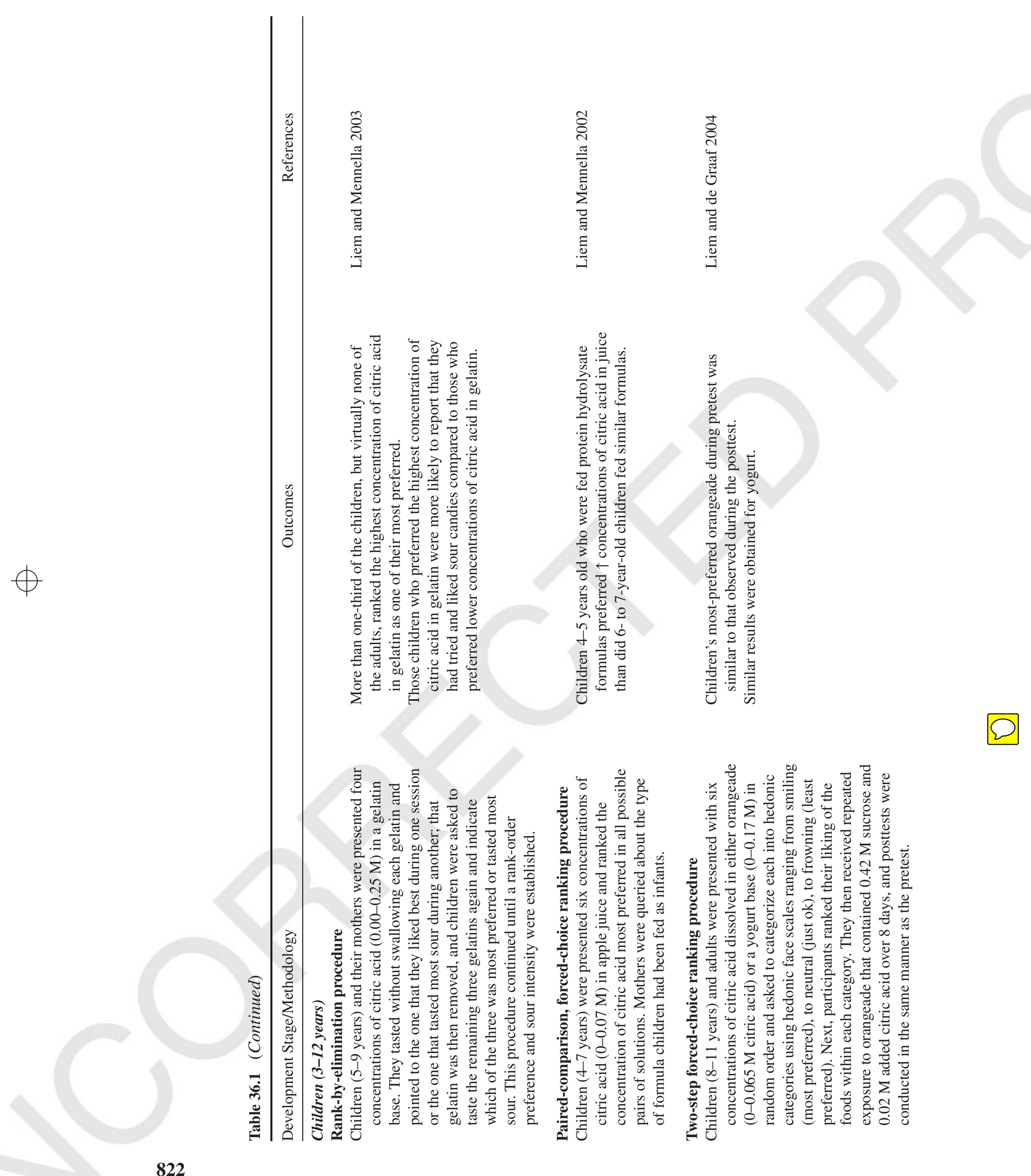


$\phi$

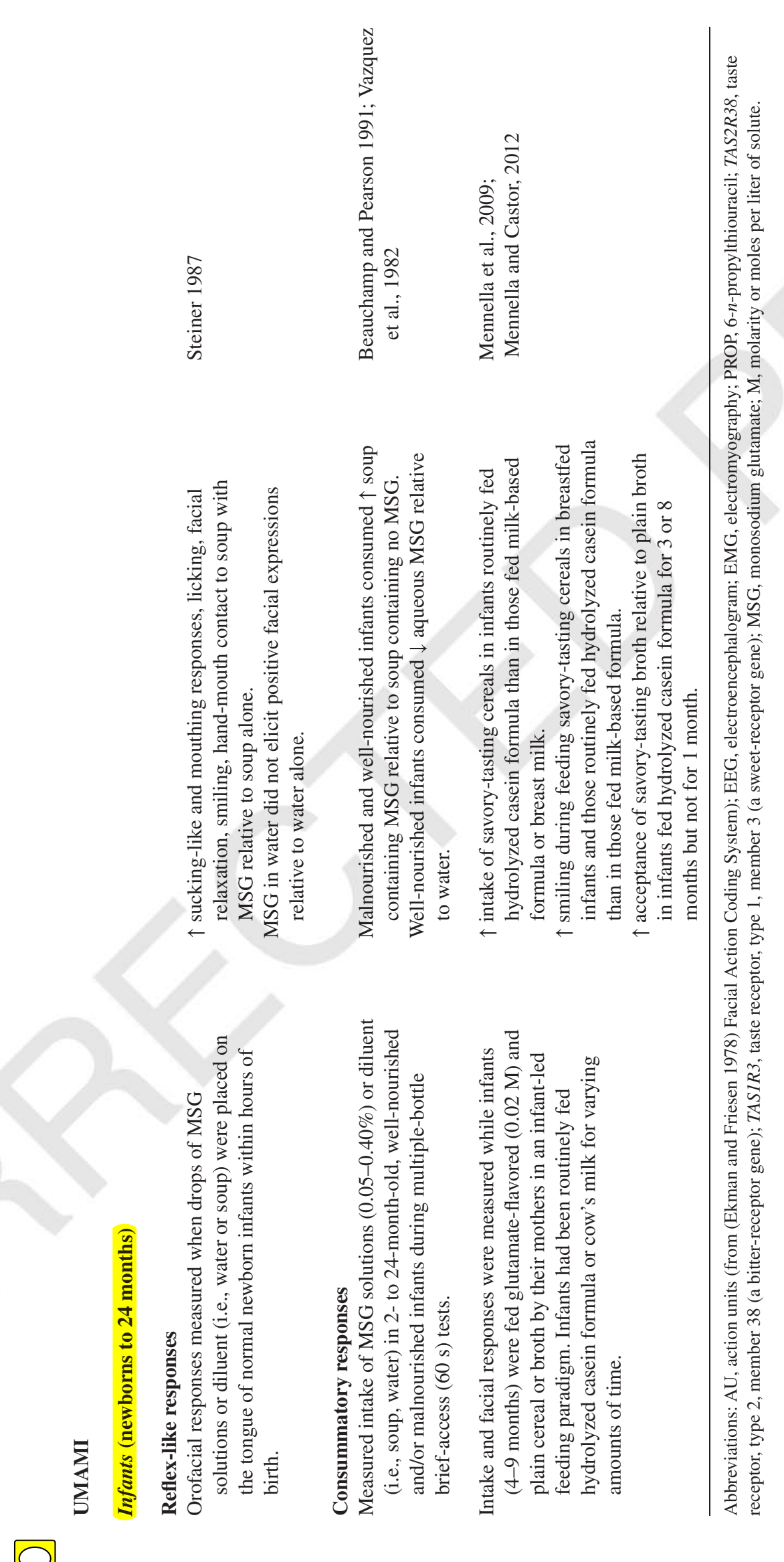


response to sour transforms into preference by 18 months of age (Blossfeld et al., 2007). By the time children have reached middle childhood, approximately one-third display a strong preference concentrated sour tastes (e.g. $0.25 \mathrm{M}$ citric acid; (Liem and Mennella 2003). These sour preferences have been shown to be related to intake of sour-tasting foods such as fruit throughout infancy (Blossfeld et al., 2007) and childhood (Liem and Mennella 2003), as well as personality characteristics, such as sensation seeking (Urbick 2000).

\subsubsection{Preferences Counter-adaptive to Our Modern World}

Why is it that children reject the very tastes that are associated with so many healthful foods, and prefer those that are associated with high-calorie, fatty foods? From an evolutionary perspective, it has been argued that children's responses to tastes enhance survival by attracting them to foods that contain energy, minerals, and vitamins (e.g., mother's milk, fruits) during periods of maximal growth and inhibiting ingestion of potentially toxic substances many of which are bitter. Children's innate taste preferences, which reflect their biological needs, help to explain why they like to eat the foods and beverages they do. For example, Coldwell et al., (2009) have shown that preferences for sweet-tasting foods are correlated with periods of high growth. In our modern society, this once adaptive link between sweet preference and biological need may leave children especially vulnerable to negative long-term consequences, including obesity and dental caries.

Although children's hedonic responses to the basic tastes may have once enhanced their survival, today children's predisposition to prefer sugar and salt and to avoid bitter-tasting foods, such as green vegetables, is no longer adaptive in an obesogenic environment that contains an overabundance of processed carbohydrate-rich and salty foods. Approximately a third of children more than 2 years of age are overweight (Ogden et al., 2010); this excess weight is associated with a number of serious health complications that were previously considered rare in children, such as type 2 diabetes and high blood pressure (Lee et al., 2006; Maynard et al., 2003). Given that unhealthful dietary patterns established in childhood track into adulthood (Mikkila et al., 2004), it is necessary to develop a thorough understanding of the basic biology of taste and the mechanisms involved in the development of taste and flavor preferences throughout childhood.

The innate rejection of bitter-tasting substances in children, in addition to reducing consumption of green vegetables, also plays a central role in children's hesitance to take oral medications (for review, see Mennella and Beauchamp 2008). Although many solid oral dosage forms (e.g., pills, tablets) have the advantage of masking or encapsulating the bitter tastes of active compounds, such methods are ineffective for many children because they often cannot or will not swallow pills or tablets. Most children, at some point in their lives, are required to take medicine, which often tastes bitter, and some will refuse to take it. When children refuse to take a single dose-let alone a full course of medication-because it tastes bad to them, that bitter taste thwarts the benefits of even the most powerful drug. Thus, the main challenge of administering medicine to children is a matter of taste because drugs, by their very nature, often taste unpleasant and bitter. The unpleasant taste of a medicine is a sensory expression of its pharmacological activity-the more potent the drug, the more bitter-tasting and/or irritating it will be. And the more bitter-tasting and irritating its flavor, the more likely the drug will be rejected by children.

A recent study explored the relationship between genotype of only one of the 25 bitter receptor genes (TAS2R38) and medication history (Lipchock et al., 2012) and found that children younger than 10 years with at least one bitter-sensitive allele (PP or AP genotype) were more likely to have taken medicine in solid formulation than were bitter-insensitive (AA genotype) children. It was hypothesized that the resistance to taking bitter liquid formulations may be related to compliance and that bitter-sensitive children may be resistant to taking bitter liquid formulations and are more motivated to try medicine in pill form as an alternative. These findings open up another important area for taste psychophysics and genetics, suggesting that taste genetics and individual differences in bitter sensitivity could be an important factor in formulation choice and compliance in the pediatric population.

\subsection{CONCLUSIONS}

Although this area of research has enjoyed more than a century of basic research, we have many gaps in knowledge in an area that has important implications for the health of our children. Although many developmentally appropriate methodologies and approaches have been created to test taste sensitivity and preference throughout childhood, more work needs to be done to validate and standardize these procedures across taste modalities. In some cases, the question may need to be asked several ways and the convergence of findings from different methodologies is required to give confidence to the conclusions.

While each measure has its limitations, the convergence of research findings supports the conclusion that the ability to detect sweets is evident very early in human development and that its hedonic tone changes throughout childhood. With respect to bitter, newborns respond with 
highly negative facial expressions to concentrated quinine and urea, but they do not reject moderate concentrations of urea. The reason for this difference remains unclear. Newborns also reject the sour taste of strong citric acid solutions; however, at least for some children, this initial rejection transforms into a preference before two years of age. Because only a handful of studies on sour tastes have been conducted, it is not known whether there are developmental changes in sensitivity or preference for sour-tasting foods and beverages. Conclusions regarding the response to savory and salty tastes are more problematic, and further research is needed. With regard to salt taste, studies measuring intake and facial expressions suggest that the newborn infant is indifferent to and may not detect salt. However, tests salt has been presented within an appropriate context (i.e., soup), children younger than two years of age have shown preferences for this taste.

The bottom line is that unhealthful behaviors, such as the overconsumption of sweet and salty foods and the rejection of bitter green vegetables or unpalatable medications, are a reflection of the child's basic biology. From an evolutionary perspective, the senses that evaluate what is put into the mouth have likely evolved to reject that which is harmful and seek out that which is beneficial. In particular, rejection of bitter-tasting and irritating substances is thought to have evolved to protect the animal from being poisoned and the plant producing these chemicals from being eaten.

That being said, our biology is not our destiny; children learn through repeated experiences with various types of foods. A case in point is sweet taste. Research has shown that children learn in which contexts sugar is typically found through experience (Beauchamp and Cowart 1985; Beauchamp and Moran 1982). That is, the sensation of sweetness may be context dependent and can acquire meaning through learning. In a recent studies, children who were exposed to a sweetened orange-flavored beverage (Liem and de Graaf 2004) or a sweetened food (Sullivan and Birch 1990) over the course of eight to fifteen days exhibited a stronger preference for the sweetened beverage or food at the end of the exposure period, but not a significant preference for the sweet taste in another context (e.g. yogurt or ricotta cheese), suggesting that this learning may be context-dependent(Liem and de Graaf 2004). That is, through familiarization, children develop a sense of what should, and what should not, taste sweet (Beauchamp and Cowart 1985; Pepino and Mennella 2005a).

Such learning is not confined to sweet taste, as evidenced by studies of salt taste perception (Beauchamp, Cowart et al., 1986; Cowart and Beauchamp 1986), as well as by studies examining more complex food media such as extensively hydrolyzed protein infant formulas (ePHF) - formulas which taste bitter, sour, and savory and have unpleasant aromas (Mennella and Beauchamp 2005). In a series of randomized clinical trials, we have shown that there is a sensitive period before 4 months of age during which experience can shift the hedonic tone to the flavor of the formula (Mennella et al., 2004; Mennella et al., 2011a). Evidence that such flavor programming lasts beyond childhood is suggested by the finding that children who were fed ePHF as infants are programmed to like the taste of not only ePHF when they are older, but also the taste of foods that are more savory (e.g., chicken) sour (e.g., lemon), and bitter (e.g., broccoli) (Liem and Mennella 2002; Mennella 1998; Mennella and Beauchamp 2002; Mennella et al., 2009; Mennella et al., 2006).

In conclusion, it is a public health priority to develop standardized psychophysical methods that are appropriate for children of all ages. More insight into the "taste world" of children will initiate new perspectives that will aid in the development of evidence-based strategies for improving children's food preferences and eating behaviors and help ameliorate bitter taste, which is the primary culprit for children's refusal to accept liquid formulations.

\section{ACKNOWLEDGMENTS}

This project was funded in part by Awards R01DC011287 from the National Institute on Deafness and Other Communication Disorders and R01HD37119 from the Eunice Kennedy Shriver National Institute of Child Health \& Human Development to J.A.M. and R15HD071486 from the Eunice Kennedy Shriver National Institute of Child Health \& Human Development to C.A.F. The content is solely the responsibility of the authors and does not necessarily represent the official views of the Eunice Kennedy Shriver National Institute of Child Health \& Human Development or the National Institutes of Health We acknowledge the expert editorial assistance of Ms. Patricia Watson.

\section{REFERENCES}

Abad, F., Diaz, N. M., Domenech, E., et al. (1996). Oral sweet solution reduces pain-related behaviour in preterm infants. Acta Paediatr. 85 854-858.

Acharya, A. B., Annamali, S., Taub, N. A. and Field, D. (2004). Oral sucrose analgesia for preterm infant venepuncture. Arch Dis Child Fetal Neonatal Ed. 89: F17-18.

Anliker, J. A., Bartoshuk, L., Ferris, A. M. and Hooks, L. D. (1991) Children's food preferences and genetic sensitivity to the bitter taste of 6-n-propylthiouracil (PROP). Am J Clin Nutr. 54: 316-320.

Armstrong, J. E., Hutchinson, I., Laing, D. G. and Jinks, A. L. (2007) Facial electromyography: responses of children to odor and taste stimuli. Chem Senses. 32: 611-621.

ASTM International 2003. E2299-03 Standard guide for sensory evaluation of products by children. Vol. 15.08, ASTM International, West Conshohocken, PA. Available at http:www.astm.org. Accessed July 2012. 
-Barr, R.G., Pantel, M.S., Young, S.N., et al. (1999). The response of crying newborns to sucrose: is it a "sweetness" effect? Physiol Behav. 66 ing newbo
$409-417$.

Beauchamp, G. K. and Cowart, B. J. (1985). Congenital and experiential factors in the development of human flavor preferences. Appetite. 6: 357-372.

Beauchamp, G. K. and Cowart, B. J. (1990). Preference for high salt concentrations among children. Dev Psychol. 26: 539-545.

Beauchamp, G. K., Cowart, B. J., Mennella, J. A. and Marsh, R. R. (1994) Infant salt taste: developmental, methodological, and contextual factors. Dev Psychobiol. 27: 353-365.

Beauchamp, G. K., Cowart, B. J. and Moran, M. (1986). Developmental changes in salt acceptability in human infants. Dev Psychobiol. 19 $17-25$.

Beauchamp, G. K. and Moran, M. (1984). Acceptance of sweet and salty tastes in 2-year-old children. Appetite. 5: 291-305.

Beauchamp, G. K. and Moran, M. (1982). Dietary experience and sweet taste preference in human infants. Appetite. 3: 139-152.

Beauchamp, G. K. and Pearson, P. (1991). Human development and umam taste. Physiol Behav. 49: 1009-1012.

Bellieni, C. V., Bagnoli, F., Perrone, S., et al. (2002). Effect of multisensory stimulation on analgesia in term neonates: a randomized controlled tria Pediatr Res. 51: 460-463.

Berridge, K. C. (1996). Food reward: brain substrates of wanting and liking. Neurosci Biobehav Rev. 20: 1-25.

Berridge, K. C. and Kringelbach, M. L. (2000). Affective neuroscience of pleasure: reward in humans and animals. Psychopharmacology (Berl). 199: 457-480.

Birch, L. L. (1998). Psychological influences on the childhood diet. J Nutr 128: 407S-410S.

Blanck, H. M., Gillespie, C., Kimmons, J. E., et al. (2008). Trends in fruit and vegetable consumption among U.S. men and women, 1994-2005. Prev Chronic Dis. 5: A35.

Blass, E. M. and Camp, C. A. (2003). Changing determinants of crying termination in 6 to 12 week-old human infants. Dev Psychobiol. 42 312-316.

Blass, E. M. and Hoffmeyer, L. B. (1991). Sucrose as an analgesic for newborn infants. Pediatrics. 87: 215-218.

Blass, E. M. and Smith, B. A. (1992). Differential effects of sucrose, fructose, glucose, and lactose on crying in 1- to 3-day-old human infants: Qualitative and quantitative considerations. Dev Psychol. 28: 804-810.

Blass, E. M. and Watt, L. B. (1999). Suckling- and sucrose-;induced analgesia in human newborns. Pain. 83: 611-623.

Blossfeld, I., Collins, A., Boland, S., et al. (2007) Relationships between acceptance of sour taste and fruit intakes in 18-month-old infants. $\mathrm{Br}$ Nutr. 98: 1084-1091.

Boughter, J. D. J. and Bachmanov, A. A. (2007). Behavioral genetics an taste. BMC Neurosci. 8 Suppl 3: S3.

Bradley, R. M. and Mistretta, C. M. (1975). The developing sense of taste. In Denton, D.A. and Coghlan, J.P. (eds.), Olfaction and Taste V. Academic Press, New York, pp. 91-98.

Bradley, R. M. and Stern, I. B. (1967). The development of the human taste bud during the foetal period. $J$ Anat. 101: 743-752.

Bucher, H. U., Baumgartner, R., Bucher, N., et al. (2000). Artificial sweetener reduces nociceptive reaction in term newborn infants. Early Hum Dev. 59: $51-60$

Bucher, H. U., Moser, T., von Siebenthal, K., et al. (1995). Sucrose reduces pain reaction to heel lancing in preterm infants: a placebo-controlled, randomized and masked study. Pediatr Res. 38: 332-335.
Carbajal, R., Chauvet, X., Couderc, S. and Olivier-Martin, M. (1999). Randomised trial of analgesic effects of sucrose, glucose, and pacifiers in term neonates. BMJ. 319: 1393-1397.

Carbajal, R., Lenclen, R., Gajdos, V., et al. (2002). Crossover trial of analgesic efficacy of glucose and pacifier in very preterm neonates during subcutaneous injections. Pediatrics. 110: 389-393.

Chambers, E. (2005). Commentary: Conducting sensory research in children. J Sens Stud. 20: 90-92.

Chen, A. W. and Resurreccion, A. V. (1996). Age appropriate hedonic scales to measure food preferences of young children. J Sens Stud. 11: 141-163.

Coldwell, S. E., Mennella, J. A., Duffy, V. B for Newelogien Behavioral Fun Neurology, in press.

Coldwell, S. E., Oswald, T. K. and Reed, D. R. (2009). A marker of growth differs between adolescents with high vs. low sugar preference. Physiol Behav. 96: 574-580.

Cowart, B. J. (1981). Development of taste perception in humans: sensitivity and preference throughout the life span. Psychol Bull. 90: 43-73.

Cowart, B. J. and Beauchamp, G. K. (1990). Early development of taste perception. In McBride, R. and MacFie, H. (eds.), Psychological Basis of Sensory Evaluation, London, England, pp. 1-17.

Cowart, B. J. and Beauchamp, G. K. (1986). The importance of sensory context in young children's acceptance of salty tastes. Child Dev. 57: 1034-1039.

Cowart, B. J., Beauchamp, G. K. and Mennella, J. A. (2004). Development of taste and smell in the neonate., Fetal and Neonatal Physiology, Volume 2, 3rd edition. Saunders, Philadelphia, PA, pp. 1819-1827.

Crook, C. K. (1976). Neonatal sucking: effects of quantity of the response-contingent fluid upon sucking rhythm and heart rate. $J$ Exp Child Psychol. 21: 539-548.

Crook, C. K. (1978). Taste perception in the newborn infant. Infant Behav Dev. 1: 52-69.

Crook, C. K. and Lipsitt, L. P. (1976). Neonatal nutritive sucking: effects of taste stimulation upon sucking rhythm and heart rate. Child Dev. 47: 518-522.

Crystal, S. R. and Bernstein, I. L. (1998). Infant salt preference and mother's morning sickness. Appetite. 30: 297-307.

de Graaf, C. and Zandstra, E. H. (1999). Sweetness intensity and pleasantness in children, adolescents, and adults. Physiol Behav. 67: 513-520.

Deshmukh, L. S. and Udani, R. H. (2002). Analgesic effect of oral glucose in preterm infants during venipuncture--a double-blind, randomized, controlled trial. J Trop Pediatr. 48: 138-141.

DeSnoo, K. (1937). Das trinkende kind im uterus. Monoats Geburtsh Gynaekol. 105: 88-97.

Desor, J., Maller, O. and Turner, R. E. (1973). Taste in acceptance of sugars by human infants. J Comp Physiol Psychol. 84: 496-501.

Desor, J. A. and Beauchamp, G. K. (1987). Longitudinal changes in sweet preferences in humans. Physiol Behav. 39: 639-641.

Desor, J. A., Greene, L. S. and Maller, O. (1975a). Preferences for sweet and salty in 9- to 15-year-old and adult humans. Science. 190: 686-687.

Desor, J. A., Maller, O. and Andrews, K. (1975b). Ingestive responses of human newborns to salty, sour, and bitter stimuli. J Comp Physiol Psychol. 89: 966-970.

Eckstein, A. (1927). Zur Physiologie der Geschmacksempfindung und des Saugreflexes bei Säuglingen. Z. Kinderheilk. 45: 1-18.

Egan, J. M. and Margolskee, R. F. (2008). Taste cells of the gut and gastrointestinal chemosensation. Mol Interv. 8: 78-81.

Ekman, P. and Freisen, W. V. (2003). Unmasking the face: a guide to recognizing emotions from facial expressions. Malor Books, Cambridge, MA 
Ekman, P. and Friesen, W. (1978). The facial action coding system. Consulting Psychologists Press, Palo Alto, CA

Ekman, P. and Oster, H. (1979). Facial expressions of emotion. Annual Review of Psychology. 30: 527-554.

Epstein, L. H. and Paluch, R. A. (1997). Habituation of facial muscle responses to repeated food stimuli. Appetite. 29: 213-224.

Fernandez, M., Blass, E. M., Hernandez-Reif, M., et al. (2003). Sucrose attenuates a negative electroencephalographic response to an aversive stimulus for newborns. J Dev Behav Pediatr. 24: 261-266.

Forestell, C. A. and Mennella, J. A. (2007). Early determinants of fruit an vegetable acceptance. Pediatrics. 120: 1247-1254.

Forestell, C. A. and Mennella, J. A. (2012). More than just a pretty face. The relationship between infant's temperament, food acceptance, and mothrers' pernt betw

Fox, N. A. and Davidson, R. J. (1986). Taste-elicited changes in facial sign of, N. A. and Davidson, R. J. (1986). Taste-elicited changes in facial signs
of emotion and the asymmetry of brain electrical activity in human new-

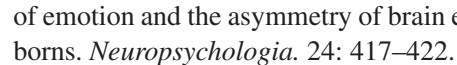

borns. Neuropsychologia. 24: 417-422.

Ganchrow, J. R. and Mennella, J. A. (2003). The ontogeny of human flavo perception. In Doty, R.L. (ed.), Hand ${ }^{\text {nd }}$ edition. Marcel Dekker. Inc., New York, pp. 823-946.

Ganchrow, J. R., Steiner, J. E., and Daher, M. (1983). Neonatal facial expressions in response to different qualities and intensities of gustatory expressions in response to different qualide
stimuli. Infant Behav. Dev. 6: 189-200.

Gibbins, S., Stevens, B., Hodnett, E., et al. (2002). Efficacy and safety of sucrose for procedural pain relief in preterm and term neonates. Nur Res. 51: 375-382.

Glendinning, J. I. (1994). Is the bitter rejection response always adaptive? Physiol Behav. 56: 1217-1227.

Glendinning, J. I., Gresack, J. and Spector, A. C. (2002). A high-throughput screening procedure for identifying mice with aberrant taste and oromotor function. Chem Senses. 27: 461-474.

Golding, J., Steer, C., Emmett, P., et al. (2009). Associations between the ability to detect a bitter taste, dietary behavior, and growth: A preliminary report. Ann. N.Y. Acad. Sci. 1170: 553-557.

Gradin, M., Eriksson, M., Holmqvist, G., et al. (2002). Pain reduction at venipuncture in newborns: oral glucose compared with local anesthetic venipuncture in newborns: oral glucos
cream. Pediatrics. 110: 1053-1057.

Graillon, A., Barr, R. G., Young, S. N., et al. (1997). Differential response to intraoral sucrose, quinine and corn oil in crying human newborns. Physiol Behav. 62: 317-325.

Greenberg, C. S. (2002). A sugar-coated pacifier reduces procedural pain in newborns. Pediatr Nurs. 28: 271-277.

Greene, L. S., Desor, J. A. and Maller, O. (1975). Heredity and experience: their relative importance in the development of taste preference in man I Comp Physiol Psychol. 89: 279-284.

Grill, H. J. and Norgren, R. (1978). The taste reactivity test. I. Mimetic responses to gustatory stimuli in neurologically normal rats. Brain Res. 143: 263-279.

Guenther, P. M., Dodd, K. W., Reedy, J. and Krebs-Smith, S. M. (2006) Most Americans eat much less than recommended amounts of fruits and vegetables. J Am Diet Assoc. 106: 1371-1379.

Guinard, J. X. (2001). Sensory and consumer testing with children. Trends Food Sci Technol. 11: 273-283.

Harris, G., Thomas, A. and Booth, D. A. (1990). Development of salt taste in infancy. Dev Psychol. 26: 534-538.

Harrison, D., Stevens, B., Bueno, M., et al. (2010). Efficacy of sweet solutions for analgesia in infants between 1 and 12 months of age: a systematic review. Arch Dis Child. 95: 406-413.

Hersch, M. and Ganchrow, D. (1980). Scanning electron microscopy of developing papillae on the tongue of human embryos and fetuses. Chemical Senses. 5: 331-341.
Hu, S., Luo, Y. J. and Hui, L. (2000). Preliminary study of association between objective parameters of facial electromyography and subjective estimates of taste palatability. Percept Mot Skills. 91: 741-747.

Hu, S., Player, K. A., McChesney, K. A., et al. (1999). Facial EMG as an indicator of palatability in humans. Physiol Behav. 68: 31-35.

Jacobs, W. W. (1978). Taste responses in wild and domestic guinea pigs. Physiol Behav. 20: 579-588.

James, C. E., Laing, D. G. and Oram, N. (1997). A comparison of the ability of 8-9-year-old children and adults to detect taste stimuli. Physiol Behav. 62: 193-197.

Jamel, H. A., Sheiham, A., Watt, R. G. and Cowell, C. R. (1997). Sweet preference, consumption of sweet tea and dental caries; studies in urban and rural Iraqi populations. Int Dent J. 47: 213-217.

Kajuira, H., Cowart, B. J. and Beauchamp, G. K. (1992). Early developmental change in bitter taste responses in human infants. Dev Psychobiol. 25: $375-386$

Keller, K. L., Reid, A., MacDougall, M. C., et al. (2010). Sex differences in the effects of inherited bitter thiourea sensitivity on body weight in 4-6-year-old children. Obesity (Silver Spring). 18: 1194-1200.

Keller, K. L., Steinmann, L., Nurse, R. J. and Tepper, B. J. (2002). Genetic taste sensitivity to 6-n-propylthiouracil influences food preference and reported intake in preschool children. Appetite. 38: 3-12.

Kim, G. H. and Lee, H. M. (2009). Frequent consumption of certain fas foods may be associated with an enhanced preference for salt taste. $J$ Hum Nutr Diet. 22: 475-480.

Knai, C., Pomerleau, J., Lock, K. and McKee, M. (2006). Getting children to eat more fruit and vegetables: a systematic review. Prev Med. 42: 85-95.

Lakkakula, A. P., Zanovec, M., Silverman, L., et al. (2008). Black children with high preferences for fruits and vegetables are at less risk of being at risk of overweight or overweight. J Am Diet Assoc. 108: 1912-1915.

Larochette, A. C., Chambers, C. T. and Craig, K. D. (2006). Genuine, suppressed and faked facial expressions of pain in children. Pain. 126 64-71.

Lee, J. M., Herman, W. H., McPheeters, M. L. and Gurney, JG. (2006). An epidemiologic profile of children with diabetes in the U.S. Diabetes Care. 29: 420-421

Lesham, M. (1998). Salt preference in adolescence is predicted by common prenatal and infantile mineral fluid loss. Physiol Behav. 63: 699-704.

Lewkowski, M. D., Barr, R. G., Sherrard, A., et al. (2003). Effects of chewing gum on responses to routine painful procedures in children. Physiol Behav. 79: 257-265.

Liem, D. G. and de Graaf, C. (2004). Sweet and sour preferences in young children and adults: role of repeated exposure. Physiol Behav. 83 $421-429$.

Liem, D. G., Mars, M. and De Graaf, C. (2004). Sweet preferences and sugar consumption of 4- and 5-year-old children: role of parents. Appetite. 43: 235-245.

Liem, D. G. and Mennella, J. A. (2003). Heightened sour preferences during childhood. Chem Senses. 28: 173-180.

Liem, D. G. and Mennella, J. A. (2002). Sweet and sour preferences during childhood: role of early experiences. Dev Psychobiol. 41: 388-395.

Liley, A. W. (1972). Disorders of amniotic fluid. In Assali, N.S. (ed.), Pathophysiology of gestation: fetal placental disorders. Academic Press, New York, pp. 157-206.

Lipchock, S. V., Reed, D. R. and Mennella, J. A. (2012). Relationship between bitter-taste receptor genotype and solid medication formulation usage among young children: a retrospective analysis. Clin Ther 34: 728-733 
Maciel, S. M., Marcenes, W. and Sheiham, A. (2001a). The relationship between sweetness preference, levels of salivary mutans streptococci and caries experience in Brazilian pre-school children. Int J Paediatr Dent 11: $123-130$.

Maciel, S. M., Marcenes, W., Watt, R. G. and Sheiham, A. (2001b). The relationship between sweetness preference and dental caries in mother/child pairs from Maringa-Pr, Brazil. Int Dent J. 51:83-88.

Maller, O. and Desor, J. A. (1973). Effect of taste on ingestion by human newborns. Symp Oral Sens Percept: 279-291.

Maone, T. R., Mattes, R. D., Bernbaum, J. C. and Beauchamp, G. K. (1990). A new method for delivering a taste without fluids to preterm and term infants. Dev Psychobiol. 13: 179-191.

Maynard, M., Gunnell, D., Emmett, P., et al. (2003). Fruit, vegetables, and antioxidants in childhood and risk of adult cancer: the Boyd Orr cohort. J Epidemiol Community Health. 57: 218-225.

McCrory, M. A., Fuss, P. J., McCallum, J. E., et al. (1999). Dietary variety within food groups: association with energy intake and body fatness in men and women. Am J Clin Nutr. 69: 440-447.

Mennella, J. A. (2007). The chemical senses and the development of flavor preferences in humans. In Hale, T.W. and Hartmann, P.E. (eds.), Textbook on Human Lactation. Hale Publishing, Texas, pp. 403-414.

Mennella, J. A. (1998). Development of the chemical senses and the programming of flavor preference. Physiologic/Immunologic Responses to Dietary Nutrients: Role of elemental and Hydrolysate Formulas in Management of the Pediatric Patient. Report of the $107^{\text {th }}$ Conference on Pediatric Research. Ross Products Division, Abbott Laboratories, Columbus, OH, pp. 201-208.

Mennella, J. A. and Beauchamp, G. K. (2002). Flavor experiences during formula feeding are related to preferences during childhood. Early Hum Dev. 68: 71-82.

Mennella, J. A. and Beauchamp, G. K. (2008). Optimizing oral medications for children. Clin Ther. 30: 2120-2132.

Mennella, J. A. and Beauchamp, G. K. (2005). Understanding the origin of flavor preferences. Chem Senses. 30 Suppl 1: i242-i243.

Mennella, J. A. and Castor, S. M. (2012). Sensitive period in flavor learning: Effects of duration of exposure to formula flavors on food likes durin infancy. Clin Nutr. In Press doi:10.1016/j.clnu.2012.05.005

Mennella, J. A., Finkbeiner, S. and Reed, D. R. (2012). The proof is in the pudding: children prefer lower fat but higher sugar than do mothers. Int J Obes (Lond): 1-7.

Mennella, J. A., Forestell, C. A., Morgan, L. K. and Beauchamp, G. K. (2009). Early milk feeding influences taste acceptance and liking durin infancy. Am J Clin Nutr. 90: 780-788S.

Mennella, J. A., Griffin, C. E. and Beauchamp, G. K. (2004). Flavor programming during infancy. Pediatrics. 113: 840-845.

Mennella, J. A., Jagnow, C. P. and Beauchamp, G. K. (2001). Prenatal and postnatal flavor learning by human infants. Pediatrics. 107: E88.

Mennella, J. A., Johnson, A. and Beauchamp, G. K. (1995). Garlic ingestion by pregnant women alters the odor of amniotic fluid. Chem Senses. 20: $207-209$

Mennella, J. A., Kennedy, J. M. and Beauchamp, G. K. (2006). Vegetable acceptance by infants: effects of formula flavors. Early Hum Dev. 82 $463-468$.

Mennella, J. A., Lukasewycz, L. D., Castor, S. M. and Beauchamp, G. K. (2011a). The timing and duration of a sensitive period in human flavor learning: a randomized trial. Am J Clin Nutr. 93: 1019-1024.

Mennella, J. A., Lukasewycz, L. D., Griffith, J. W. and Beauchamp, G. K. (2011b). Evaluation of the Monell forced-choice, paired-comparison tracking procedure for determining sweet taste preferences across the lifespan. Chem Senses. 36: 345-355.
Mennella, J. A., Pepino, M. Y. and Beauchamp, G. K. (2003). Modification of bitter taste in children. Dev Psychobiol. 43: 120-127.

Mennella, J. A., Pepino, M. Y., Duke, F. F. and Reed, D. R. (2010a). Age modifies the genotype-phenotype relationship for the bitter receptor TAS2R38. BMC Genet. 11: 60.

Mennella, J. A., Pepino, M. Y., Lehmann-Castor, S. M. and Yourshaw, L. M. (2010b). Sweet preferences and analgesia during childhood: effects of family history of alcoholism and depression. Addiction. 105. 666-675. Mennella, J. A., Pepino, M. Y. and Reed, D. R. (2005). Genetic and environmental determinants of bitter perception and sweet preferences. Pediatrics. 115: e216-222.

Mikkila, V., Rasanen, L., Raitakari, O. T., et al. (2004). Longitudinal changes in diet from childhood into adulthood with respect to risk of cardiovascular diseases: The Cardiovascular Risk in Young Finns Study. Eur J Clin Nutr. 58: 1038-1045.

Miller, A., Barr, R. G. and Young, S. N. (1994). The cold pressor test in children: methodological aspects and the analgesic effect of intraoral sucrose. Pain. 56: 175-183.

Miller, J. L., Sonies, B. C. and Macedonia, C. (2003). Emergence of oropharyngeal, laryngeal and swallowing activity in the developing fetal upper aerodigestive tract: an ultrasound evaluation. Early Hum Dev. 71: 61-87.

Mistretta, C. M. (1972). Topographical and histological study of the developing rat tongue, palate and taste buds. In Bosma, J.F. (ed.), Third Symoping rat tongue, palate and taste buds. In Bosma, J.F. (ed.), Third Sym-
posium on Oral Sensation and Perception: The Mouth of the Infant. C.C. posium on Oral Sensation and Perception:
Thomas, Springfield, IL, pp. 163-186.

Mokdad, A. H., Marks, J. S., Stroup, D. F. and Gerberding, J. L. (2004). Actual causes of death in the United States, 2000. JAMA. 291: 1238-1245.

Nowlis, G. H. and Kessen, W. (1976). Human newborns differentiate differing concentrations of sucrose and glucose. Science. 191: 865-866.

Ogden, C. L., Carroll, M. D., Curtin, L. R., et al. (2010). Prevalence of high body mass index in US children and adolescents, 2007-2008. JAMA. 303: 242-249.

Okan, F., Coban, A., Ince, Z., et al. (2007). Analgesia in preterm newborns: the comparative effects of sucrose and glucose. Eur J Pediatr. 166: 1017-1024.

Pepino, M. Y. and Mennella, J. A. (2005a). Factors contributing to individual differences in sucrose preference. Chem Senses. 30 Suppl 1: i319-i320.

Pepino, M. Y. and Mennella, J. A. (2005b). Sucrose-induced analgesia is related to sweet preferences in children but not adults. Pain. 119: 210-218.

Peterson, F. and Rainey, L. H. (1910). The beginnings of mind in the newborn. Bull Lying-In Hosp 7: 99-122.

Popper, R. and Kroll, J. J. (2005). Conducting sensory research with children. J Sens Stud. 20: 75-87.

Pritchard, J. A. (1965). Deglutition by Normal and Anencephalic Fetuses. Obstet Gynecol. 25: 289-297.

Ramenghi, L. A., Evans, D. J. and Levene, M. I. (1999). "Sucrose analgesia": absorptive mechanism or taste perception? Arch Dis Child Fetal Neonatal Ed. 80: F146-147.

Ramenghi, L. A., Griffith, G. C., Wood, C. M. and Levene, M. I. (1996) Effect of non-sucrose sweet tasting solution on neonatal heel prick responses. Arch Dis Child Fetal Neonatal Ed. 74: F129-131.

Rosenstein, D. and Oster, H. (1988). Differential facial responses to four basic tastes in newborns. Child Dev. 59: 1555-1568.

Ross, M. G. and Nijland, M. J. (1997). Fetal swallowing: relation to amniotic fluid regulation. Clin Obstet Gynecol. 40: 352-365.

Schmidt, H. J. and Beauchamp, G. K. (1988). Adult-like odor preferences and aversions in three-year-old children. Child Dev. 59: 1136-1143. 
Schuett, V. E., Brown, E. S. and Michals, K. (1985). Reinstitution of diet therapy in PKU patients from twenty-two clinics. Am J Public Health. 75: $39-42$.

Schwartz, C., Issanchou, S. and Nicklaus, S. (2009). Developmental changes in the acceptance of the five basic tastes in the first year of life. Br J Nutr. 102: 1375-1385.

Sclafani, A. (2007). Sweet taste signaling in the gut. Proc Natl Acad Sci USA. 104: 14887-14888.

Segovia, C., Hutchinson, I., Laing, D. G. and Jinks, A. L. (2002). A quan titative study of fungiform papillae and taste pore density in adults an children. Brain Res Dev Brain Res. 138: 135-146.

Smith, B. A. and Blass, E. M. (1996). Taste-mediated calming in premature, preterm, and full-term human infants. Dev Psychol. 32: 1084-1089.

Spector, A. C., Smith, J. C. and Hollander, G. R. (1981). A comparison of dependent measures used to quantify radiation-induced taste aversion. Physiol Behav. 27: 887-901.

Spector, A. C. and Travers, S. P. (2005). The representation of taste quality in the mammalian nervous system. Behav Cogn Neurosci Rev. 4 143-191

Stein, L. J., Cowart, B. J. and Beauchamp, G. K. (2012). The development of salty taste acceptance is related to dietary experience in human infants: of salty taste acceptance is related to dietary experienc

Stein, N., Laing, D. G. and Hutchinson, I. (1994). Topographical differences in sweetness sensitivity in the peripheral gustatory system of adult and children. Brain Res Dev Brain Res. 82: 286-292.

Steiner, J. E. (1973). The gustofacial response: Observation on normal and anencephalic newborn infants. In Bosma. J. F. (ed), Fourth Symposiun anencel and Welfare, Bethesda, pp. 254-278.

Steiner, J. E. (1977). Facial expressions of the neonate infant indicating the hedonics of food-related chemical stimuli. Taste and development: the genesis of sweet preference. U.S. Government Printing Office, Washing ton, DC.

Steiner, J. E. (1979). Human facial expressions in response to taste and smell stimulation. Adv. Child Dev. Behav. 13: 257-295.

Steiner, J. E. (1987). What the Neonate Can Tell Us About Umami. In Kawamura, Y. and Kare, M.R. (eds.), Umami: A Basic Taste. Marcel Dekker, New York, pp. 97-103.

Steiner, J. E, Glaser, D., Hawilo, M. E. and Berridge, K. C. (2001). Comparative expression of hedonic impact: affective reactions to taste by human infants and other primates. Neurosci Biobehav Rev. 25: 53-74.

Stevens, B., Yamada, J., Beyene, J., et al. (2005). Consistent management of repeated procedural pain with sucrose in preterm neonates: Is it effective and safe for repeated use over time? Clin J Pain. 21: 543-548.
Stevens, B., Yamada, J. and Ohlsson, A. (2010). Sucrose for analgesia in newborn infants undergoing painful procedures. Cochrane Database Syst Rev:CD001069.

Sullivan, S. A. and Birch, L. L. (1990). Pass the sugar, pass, the salt: experience dictates preference. Dev Psychol. 26: 546-551.

Tatzer, E., Schubert, M. T., Timischl, W. and Simbruner, G. (1985). Discrimination of taste and preference for sweet in premature babies. Early Hum Dev. 12: 23-30.

Temple, E. C., Hutchinson, I., Laing, D. G. and Jinks, A. L. (2002a). Taste development: differential growth rates of tongue regions in humans. Brain Res Dev Brain Res. 135: 65-70.

Temple, E. C., Laing, D. G., Hutchinson, I. and Jinks, A. L. (2002b). Temporal perception of sweetness by adults and children using computerized time-intensity measures. Chem Senses. 27: 729-737.

Tomita, N. E., Nadanovsky, P., Vieira, A. L. and Lopes, E. S. (1999). [Taste preference for sweets and caries prevalence in preschool children]. Re Saude Publica. 33: 542-546.

Turnbull, B. and Matisoo-Smith, E. (2002). Taste sensitivity to 6-n-propylthiouracil predicts acceptance of bitter-tasting spinach in 3-6-y-old children. Am J Clin Nutr. 76: 1101-1105.

Urbick, B. (2000). Part two: what we have learned about kids. In Urbrick, B. (ed.), What about Kids: Food and Beverages. Leatherhead Publishing, Surrey, pp. 17-39.

Vazquez, M., Pearson, P. B. and Beauchamp, G. K. (1982). Flavor preferences in malnourished Mexican infants. Physiol Behav. 28: 513-519.

Verma, P., Mittal, S., Ghildiyal, A., et al. (2007). Salt preference: age an sex related variability. Indian J Physiol Pharmacol. 51: 91-95.

Visser, J., Kroeze, J. H., Kamps, W. A. and Bijleveld, C. M. (2000). Testing taste sensitivity and aversion in very young children: development of a procedure. Appetite. 34: 169-176

Watson, W. L., Laing, D. G., Hutchinson, I. and Jinks, A. L. (2001). Identification of the components of taste mixtures by adults and children. $D e$ Psychobiol. 39: 137-145.

Witt, M. and Reutter, K. (1996). Embryonic and early fetal development of human taste buds: a transmission electron microscopical study. Anat Rec. 246: 507-523.

Witt, M. and Reutter, K. (1998). Innervation of developing huma taste buds. An immunohistochemical study. Histochem Cell Biol. 109: 281-291.

Wotman, S., Mandel, I. D., Khotim, S., et al. (1964). Salt taste threshold and cystic fibrosis. Am J Dis Child. 108: 372-374.

Zeifman, D., Delaney, S. and Blass, E. M. (1996). Sweet taste, looking, and calm in 2- and 4-week-old infants: the eyes have it. Dev Psychol. 22 1090-1099. 
